\title{
Scenario-Based Network Reconfiguration and Renewable Energy Resources Integration in Large-Scale Distribution Systems Considering Parameters Uncertainty
}

\author{
Ziad M. Ali ${ }^{1,2, *(\mathbb{D}}$, Ibrahim Mohamed Diaaeldin ${ }^{3}{ }^{\circ}$, Shady H. E. Abdel Aleem ${ }^{4,5}{ }^{(}$, Ahmed El-Rafei ${ }^{3}{ }^{(}$, \\ Almoataz Y. Abdelaziz ${ }^{6}$ (D) and Francisco Jurado ${ }^{7}(\mathbb{D}$ \\ 1 Electrical Engineering Department, College of Engineering at Wadi Addawaser, \\ Prince Sattam Bin Abdulaziz University, Wadi Addawaser 11991, Saudi Arabia \\ 2 Electrical Engineering Department, Aswan faculty of Engineering, Aswan University, Aswan 81542, Egypt \\ 3 Engineering Physics and Mathematics Department, Ain Shams University, Cairo 11517, Egypt; \\ ibrahimmohamed@eng.asu.edu.eg (I.M.D.); ahmed.elrafei@eng.asu.edu.eg (A.E.-R.) \\ 4 Technology and Maritime Transport, Electrical Energy Department, \\ The College of Engineering and Technology, Arab Academy for Science, Giza 12577, Egypt; \\ engyshady@ieee.org \\ 5 Power Quality Solutions Department, ETA Electric Company, 410 Al Haram St., El Omraniya, \\ Giza 12111, Egypt \\ 6 Faculty of Engineering and Technology, Future University in Egypt, Cairo 11835, Egypt; \\ almoatazabdelaziz@hotmail.com \\ 7 Department of Electrical Engineering, University of Jaén, EPS Linares, 23700 Jaén, Spain; fjurado@ujaen.es \\ * Correspondence: dr.ziad.elhalwany@aswu.edu.eg
}

\section{check for} updates

Citation: Ali, Z.M.; Diaaeldin, I.M.; H. E. Abdel Aleem, S.; El-Rafei, A.; Abdelaziz, A.Y.; Jurado, F. Scenario-Based Network Reconfiguration and Renewable Energy Resources Integration in Large-Scale Distribution Systems Considering Parameters Uncertainty. Mathematics 2021, 9, 26

https://dx.doi.org/10.3390/ math9010026

Received: 10 November 2020 Accepted: 22 December 2020 Published: 24 December 2020

Publisher's Note: MDPI stays neutral with regard to jurisdictional claims in published maps and institutional affiliations.

Copyright: () 2020 by the authors. Licensee MDPI, Basel, Switzerland. This article is an open access article distributed under the terms and conditions of the Creative Commons Attribution (CC BY) license (https: / / creativecommons.org/ licenses/by/4.0/).

\begin{abstract}
Renewable energy integration has been recently promoted by many countries as a cleaner alternative to fossil fuels. In many research works, the optimal allocation of distributed generations (DGs) has been modeled mathematically as a DG injecting power without considering its intermittent nature. In this work, a novel probabilistic bilevel multi-objective nonlinear programming optimization problem is formulated to maximize the penetration of renewable distributed generations via distribution network reconfiguration while ensuring the thermal line and voltage limits. Moreover, solar, wind, and load uncertainties are considered in this paper to provide a more realistic mathematical programming model for the optimization problem under study. Case studies are conducted on the 16-, 59-, 69-, 83-, 415-, and 880-node distribution networks, where the 59- and 83-node distribution networks are real distribution networks in Cairo and Taiwan, respectively. The obtained results validate the effectiveness of the proposed optimization approach in maximizing the hosting capacity of DGs and power loss reduction by greater than $17 \%$ and $74 \%$, respectively, for the studied distribution networks.
\end{abstract}

Keywords: distributed generation; graphically based network reconfiguration; hosting capacity maximization; power loss minimization; bilevel multi-objective nonlinear programming optimization; DG uncertainty; load uncertainty; TOPSIS; large distribution networks

\section{Introduction}

Wide integration of renewable energies has been promoted in many countries [1,2]. The decentralized allocation of renewable distributed generations (DGs) has been supported by distribution system operators (DSOs) to cover loads at peak loading durations, reduce the loading on distribution systems' transformers, and also minimize the total active loss; however, this led to many operational problems, including line thermal limits overloading, overvoltage violations, harmonic overloading, and others. Thus, the requirements for optimal DGs planning has become essential to attain lower operational issues.

Recently, the concept of DGs hosting capacity (HC) was raised in many research works [3], aiming to improve the system performance for the accommodation of more DGs. 
The HC study of the distribution networks hinges on assessing the maximum penetration of DGs that can be accommodated by the distribution networks while maintaining the system's operational limits within acceptable boundaries and also minimizing the upcoming issues arising from increasing DGs maximization, including harmonic currents injected due to renewable energies' inverters [4], reverse power flows [5], derating of distribution cables [6], and others. As a result, DGs penetration or HC assessment was carried out by adopting various strategies to mitigate the aforementioned problems from different operational and planning perspectives [3].

In the literature, various approaches were employed to increase DGs penetration via promising strategies, which have proven their ability to maximize the $\mathrm{HC}$ of the distribution networks of different sizes [3]. These strategies include distribution network reconfiguration (DNR) [7,8], soft open points (SOPs) [9,10], network reinforcement [11], harmonic contents reduction [12,13], static var compensator [14], and others. HC was assessed in Reference [7] for a real large distribution network in Japan composed of 235 switches via choosing the optimal configurations arising from enumerating the partial networks. Multi-period optimal power flow is formulated in Reference [8] to maximize the HC of the 34-node distribution network. In Reference [9], HC was assessed for the 83-node distribution network using multiple SOPs and DGs allocation along with DNR. HC was measured for a real project in Great Britain, aiming to join two networks via an SOP [10]. In Reference [11], a new network reinforcement index called ' $F R I^{\prime}$ was proposed to increase the capability of delivering active powers from multiple pre-allocated DG units on an Egyptian real distribution network. Moreover, HC was assessed for the non-sinusoidal 18-and 33-node distribution networks solved by the decoupled harmonic power flow [12]. Moreover, in Reference [13], the HC was maximized via a C-type filter allocated in shunt with the photovoltaic (PV) DG. In Reference [14], optimal planning of static var compensators (SVCs) was carried out along with the HC maximization of PV units using a stochastic multi-stage optimization approach. However, most of these research works used to assess the $\mathrm{HC}$ of the distribution network from the deterministic/probabilistic viewpoint, without considering wind turbine (WT) and solar photovoltaic (PV) units together, under load uncertainties for large distribution networks. Thus, it is important to consider these uncertainties while assessing the maximum HC of the distribution networks. Furthermore, the operational losses were not considered during $\mathrm{HC}$ analysis; thus, a multi-objective formulation will be useful to assess the $\mathrm{HC}$ while considering the network losses.

In the recent past, various research optimization methodologies, including mathematical and heuristic/metaheuristic optimization techniques, were employed to reconfigure large distribution networks. From the mathematical techniques' standpoint, in Reference [15], mixed-integer cone programming and mixed-integer linear programming formulations were employed to reconfigure large distribution networks up to the 830-node distribution network. Mixed-integer quadratic programming was formulated in Reference [16] to reconfigure large distribution networks up to the 880-node distribution network, where a linear load flow takes place to reduce the computational time. A mixed-integer second-order cone programming optimization problem was formulated in Reference [17], based on the AC power flow convexification to optimize large distribution networks up to the 880-node distribution network. A novel graphically based DNR algorithm [18] was proposed in 2019, which is capable of reconfiguring the large distribution networks up to the 4400-node distribution network in a short time using MATLAB. From the heuristic/metaheuristic techniques' standpoint, many optimization techniques were employed to reconfigure distribution networks [19]. A tabu search algorithm was employed in Reference [20] to reconfigure radial distribution feeders up to the 118-node distribution network. A novel reconfiguration methodology was proposed in Reference [21] to regenerate a radial configuration from the best configuration of the distribution network via the expanded invasive weed optimization algorithm. A fast non-dominated sorting guided genetic algorithm was proposed in Reference [22] to minimize the power losses, load balancing, switching actions, and also voltage profile improvement via DNR of the 16-, 69-, and 136-node distribution networks. In Reference [23], a very time-efficient optimization approach was proposed by Roberge et al. to optimize large distribution networks 
up to the 4400-node distribution networks via Cuda programming implementation for the DNR optimization problem.

In this work, a multi-objective bilevel optimization approach is employed to assess the maximum $\mathrm{HC}$ and also maximize the total power loss reduction of six distribution networks up to the 880-node large distribution network. The optimization process is conducted by setting two optimization levels, i.e., the upper and the lower levels, to address the planning, and operation viewpoints, simultaneously. In the upper level, two multi-objective optimization techniques, including multi-objective non-dominated sorting genetic algorithm (NSGA-II) [24] and multi-objective particle swarm optimization (MOPSO) [25] are employed to maximize two objectives, including HC maximization of the distribution networks and maximization of the total power loss reduction. In the lower level, the graphically based DNR algorithm in Reference [18] takes place to maximize the power loss reduction of the distribution network at each scenario.

In this work, the main contributions are listed as follows:

(1). Optimal allocation of WTs and PVs is performed while considering their uncertainties, including wind speed and solar irradiance, respectively.

(2). Load uncertainty is considered in this study to step on the real-life benefits of DGs penetration during load alterations.

(3). A bilevel multi-objective optimization approach is formulated to optimally size renewable WT/PV DGs along with network optimization from the planning and operational perspectives. Further, the optimal solution is chosen from the pareto solutions via a decision-making algorithm called 'Technique for Order of Preference by Similarity to Ideal Solution' (TOPSIS).

(4). Case studies are conducted on real distribution networks, including the 59-node distribution network in Cairo and the 83-node distribution network of the Taiwan power company. Furthermore, the proposed optimization approach is tested on the 415-and 880-node large distribution networks, which are ensembled from the 83- node real distribution network.

The organization of this work is enclosed in five sections. Section 2 provides the problem statement of this work, which is composed of the power flow equations, the DNR graphically based algorithm, the WT, and PV modeling, the used scenarios generation algorithm, and TOPSIS. Section 3 formulates the bilevel multi-objective optimization approach used in this paper. Section 4 encloses the results and commentary on the obtained results. Finally, Section 5 briefly illustrates the research outcomes and future recommendations.

\section{Materials and Methods}

In this section, the power flow equations, the graphically based DNR mathematical algorithm, load, WT, PV DGs' models, TOPSIS, and system performance indices are illustrated in detail. Figure 1 demonstrates distribution network modeling for the upcoming case studies.

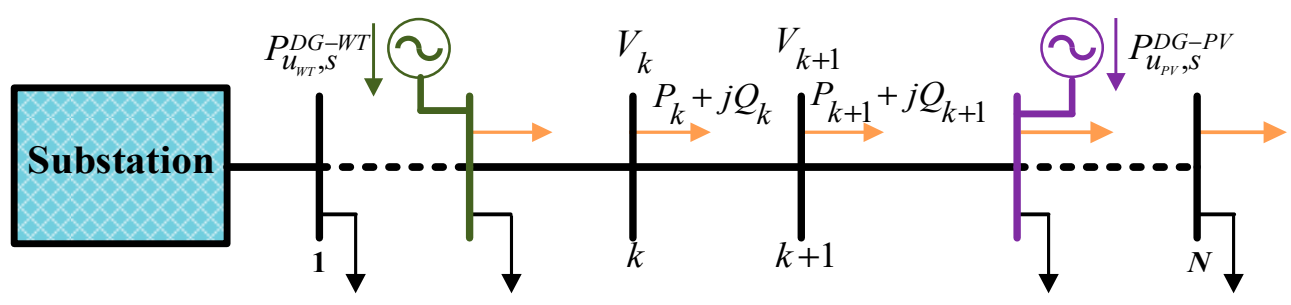

Figure 1. Distribution network model.

\subsection{Power Flow Equations}

The power flow equations used to calculate injected active/reactive power and the nodal voltages are illustrated as follows [18]:

$P_{k+1}=P_{k}-P_{k+1}^{L}-r_{b} \cdot\left(P_{k}^{2}+Q_{k}^{2}\right) /\left|V_{k}\right|^{2}, \forall k \in B^{\text {node }}, b \in B^{\text {line }}$ 


$$
\begin{gathered}
Q_{k+1}=Q_{k}-Q_{k+1}^{L}-x_{b} \cdot\left(P_{k}^{2}+Q_{k}^{2}\right) /\left|V_{k}\right|^{2}, \forall k \in B^{\text {node }}, b \in B^{\text {line }} \\
\left|V_{k+1}\right|^{2}=\left|V_{k}\right|^{2}-2 \cdot\left(r_{b} P_{k}+x_{b} Q_{k}\right)+\left(r_{b}^{2}+x_{b}^{2}\right) \cdot\left(P_{k}^{2}+Q_{k}^{2}\right) /\left|V_{k}\right|^{2}, \forall k \in B^{\text {node }}, b \in B^{\text {line }}
\end{gathered}
$$

where $P_{k}$ and $Q_{k}$ are the components of the apparent power injected to the $k$ th node; $P_{k}^{L}$ and $Q_{k}^{L}$ are the load's components at the $k$ th node; $r_{b}$ and $x_{b}$ are the impedance components at the $b$ th line; $V_{k}$ is the nodal voltage at the $k$ th node; and $B^{\text {node }}$ and $B^{\text {line }}$ are the set of nodes and lines, respectively.

\subsection{Distribution Network Reconfiguration}

Recently, in 2019, a novel graphically based DNR mathematical algorithm [18] was proposed by the authors to find a near-global/global positioning of tie-lines for large distribution networks. It has proven its ability to find near-global solutions in a short computational time for large distribution networks up to the 4400-node distribution network. The reconfiguration procedure takes place by exchanging the status of the existing tie-lines of the best configuration $\left(X_{r e c}^{b e s t}\right)$ obtained with their neighboring sectionalized lines, after being prioritized by an efficient index called weighted voltage deviation in$\operatorname{dex}(W V D)$ to obtain many temporary configurations $\left(X_{\text {rec }}^{t e m p}\right)$, which are further checked for optimality. Furthermore, this DNR mathematical algorithm has proven its ability to reconfigure the distribution networks without the need for a radiality check, and unlike the other heuristic optimizers, it does not depend on any random generations. The reader can refer to the details of this methodology in Reference [18]. The MATLAB code used to reconfigure the 59-node distribution network is provided in Reference [26], in which the MATPOWER $[27,28]$ toolbox is used for the power flow solution. Figure 2a-c illustrates the status exchange procedure between the tie-lines (dotted lines) and their neighboring sectionalized lines (highlighted in red) to obtain a better loss minimization. In the first iteration, as shown in Figure 3b, the tie line connecting the nodes 18 and 50 is changed to sectionalized (highlighted in red), and the sectionalized line joining nodes 49 and 50 is changed to a tie-line (highlighted in green) to obtain a better configuration that provides a minimum power loss than that in the initial configuration. The convergence curves for power loss minimization using this DNR method are shown in Figure 3 for the 59-, 69-, 135-, and 415-node distribution networks [18], where they reached the optimal fitness at the 11th, 6th, 14th, and 55th iteration, respectively.

\subsection{DG modeling}

Two DG types, WT and PV, are considered in this work. Detailed modeling of these DGs is illustrated in the following subsections in detail.

\subsubsection{Wind Turbine DG}

WTs are characterized by their intermittent nature due to the variations occurring in the wind speed. To model the WT, three wind speeds are mentioned to characterize the installed $\mathrm{WT}$, including rated speed $\left(v_{\text {rated }}\right)$, cut-in speed $\left(v_{\text {cut-in }}\right)$, and cut-out speed $\left(v_{c u t-o u t}\right)$. Thus, the WT injected power $\left(P_{u_{W T}, s}^{D G-W T}\right)$ at the $u_{W T}$ node $[29,30]$ for the $s$ th scenario is expressed as follows:

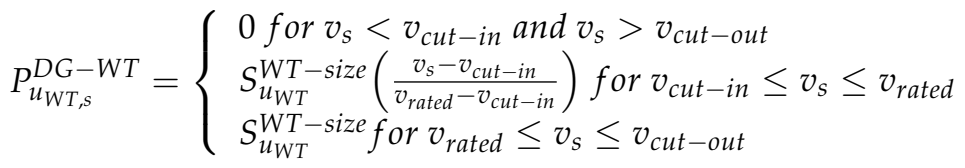

$$
\begin{aligned}
& S_{u_{W T}}^{W T-s i z e} \leq S_{W T}^{\max }
\end{aligned}
$$

where, $v_{S}$ is the wind speed at the sth scenario, $S_{u_{W T}}^{W T}$-size is the size of the installed WT at the $u_{W T}$ node, and $S_{W T}^{\text {rated }}$ is the maximum capacity of the installed WT. 


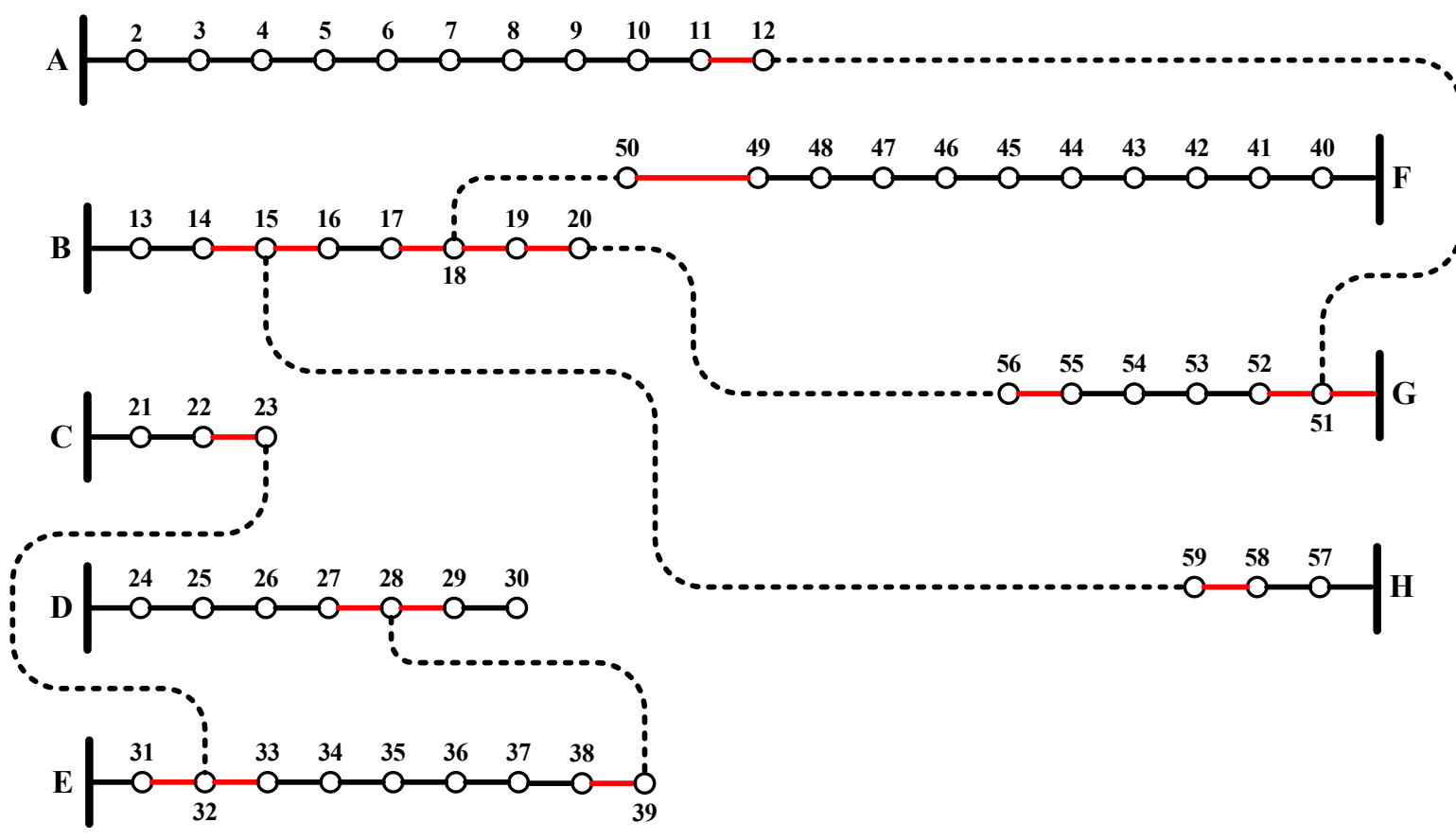

(a)

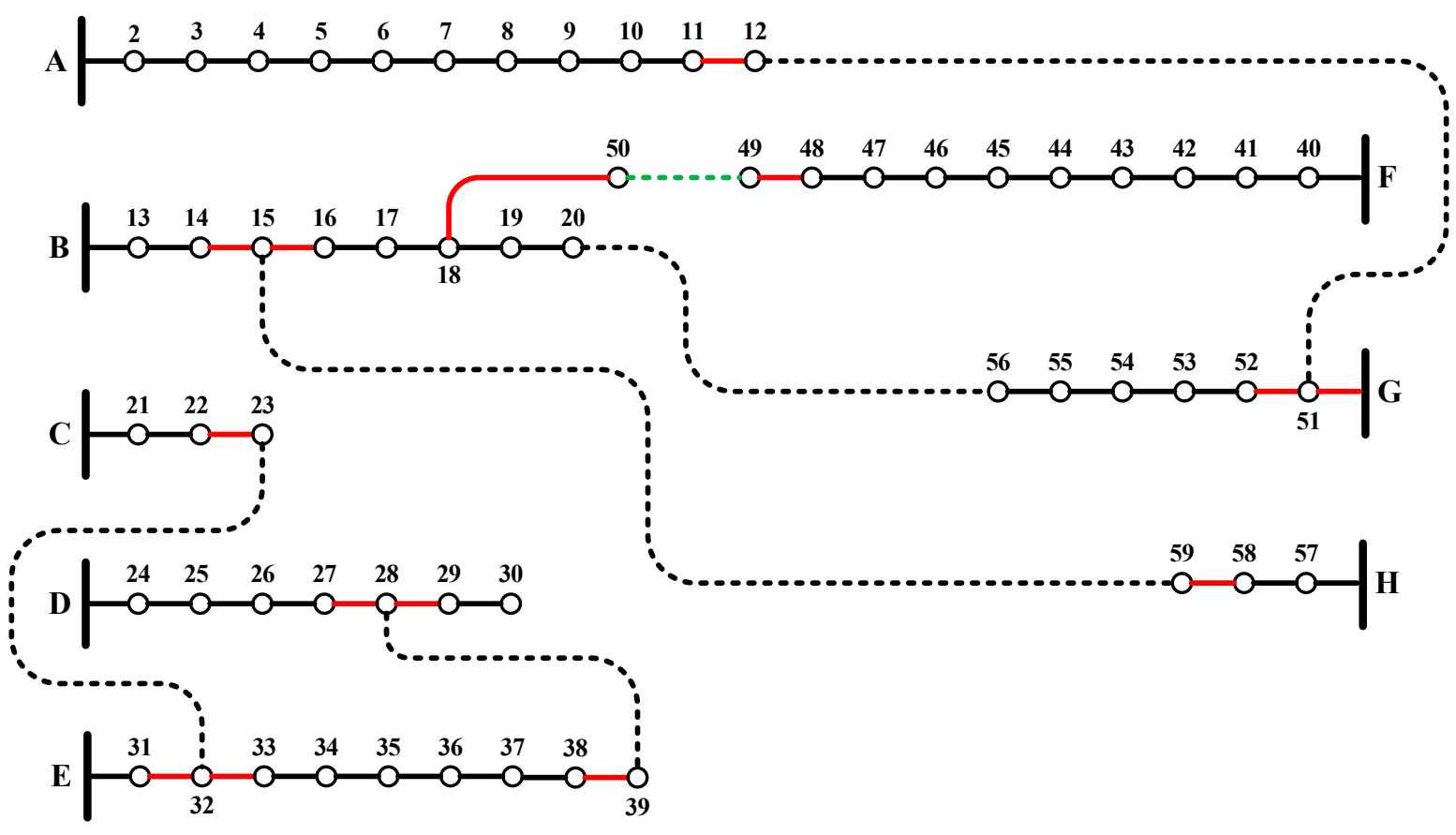

(b)

Figure 2. Cont. 


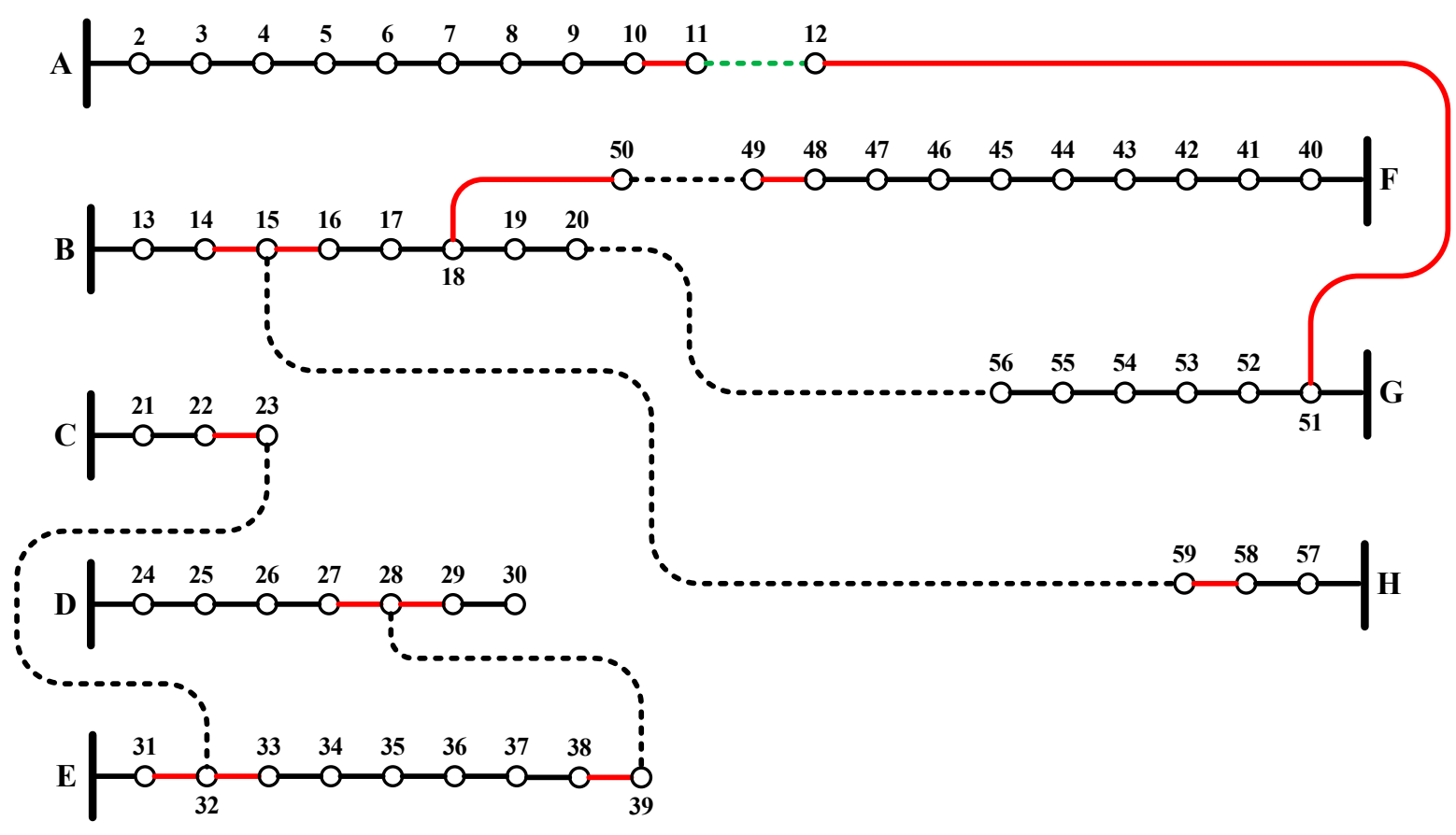

(c)

Figure 2. Reconfiguration process for the 59-node distribution network: (a) Initial configuration, (b) 1st iteration configuration, and (c) 2nd iteration configuration.

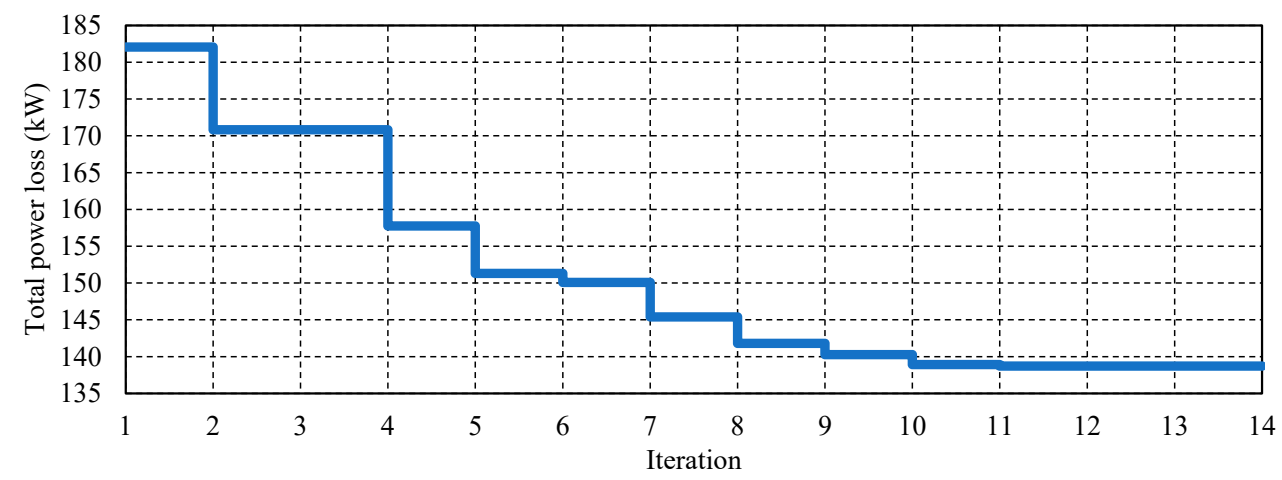

(a)

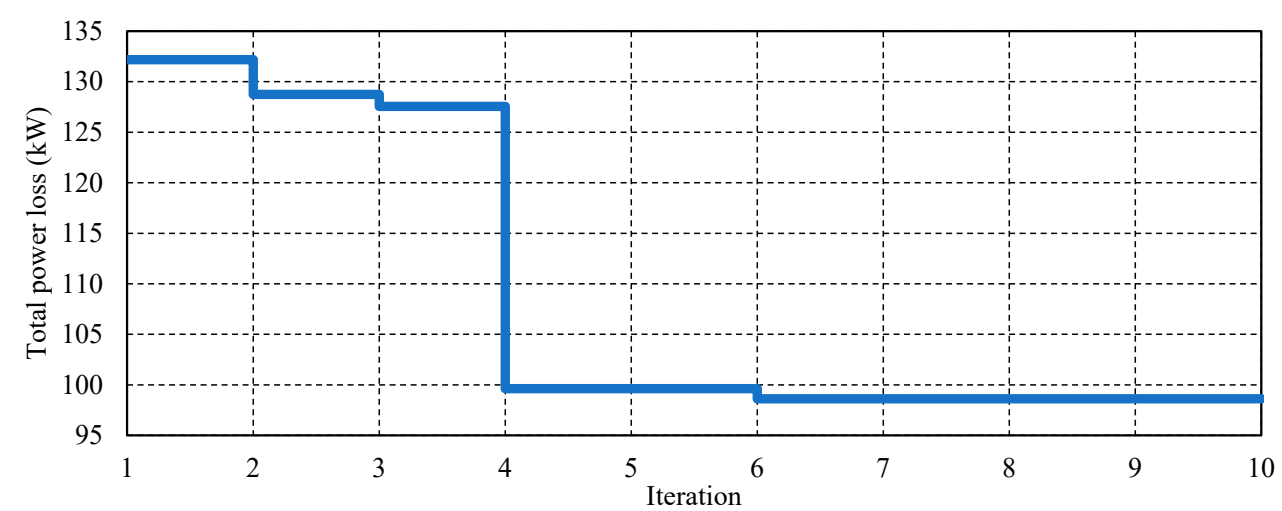

(b)

Figure 3. Cont. 


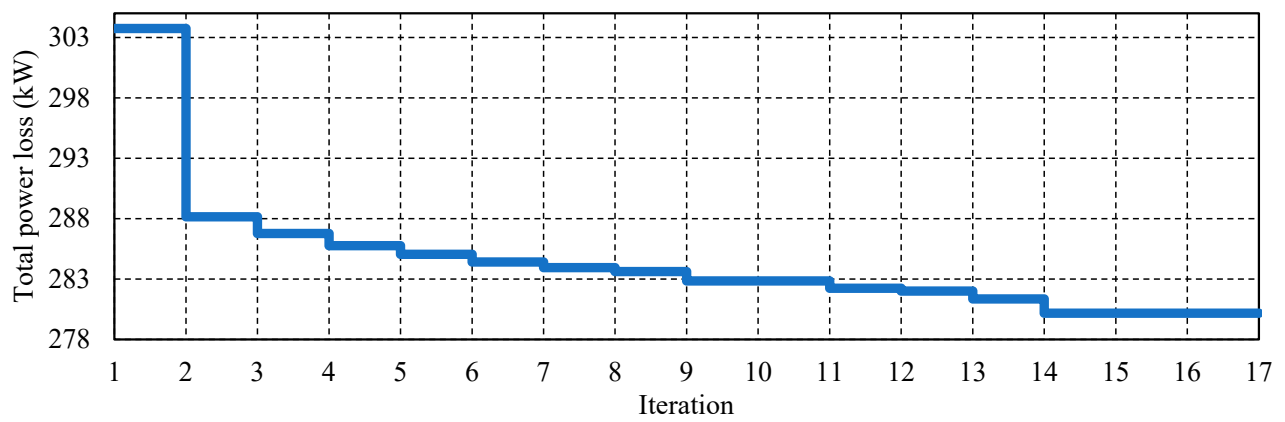

(c)

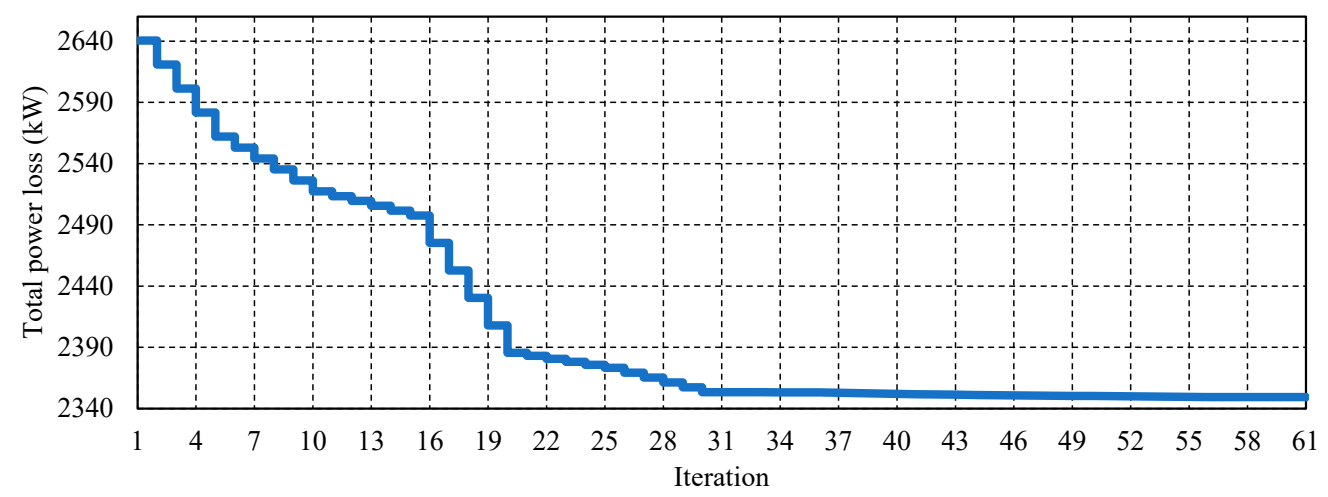

(d)

Figure 3. Convergence curves: (a) 59-node, (b) 69-node, (c) 135-node, and (d) 415-node.

\subsubsection{Solar Photovoltaic DG}

PVs are characterized by their intermittent nature due to the variations occurring in the solar irradiance $(G)$. To model the PV DG, two specific irradiance points are characterizing the output power from the PV unit $[29,30]$, including the standard solar irradiance $\left(G_{s t d}\right)$ and a specific irradiance threshold $\left(R_{c}\right)$. The solar PV penetration is controllable since it can be controlled through power trackability or by charging batteries, thus the actual penetration of a PV DG $\left(P_{u_{P V}, s}^{D G-P V}\right)$ at the sth scenario is modeled as follows [29,30]:

$$
\begin{aligned}
& P_{u_{P V}, s}^{D G-P V}=\left\{\begin{array}{l}
S_{u_{P V}}^{P V-\text { size }}\left(\frac{G_{s}^{2}}{G_{s t d} R_{c}}\right) \text { for } 0<G_{s}<R_{c} \\
S_{u_{P V}}^{P V-s i z e}\left(\frac{G_{s}}{G_{s t d}}\right) \text { for } G_{s} \geq R_{c}
\end{array}\right. \\
& S_{u_{P V}}^{P V-s i z e} \leq S_{P V}^{\max }
\end{aligned}
$$

where $G_{S}$ is the solar irradiance at the sth scenario, $S_{u_{P V}}^{P V-s i z e}$ is the size of the installed PV unit at the $u_{P V}$ node, and $S_{P V}^{\max }$ is the maximum capacity of the installed PV.

\subsection{Scenarios Reduction}

In this work, the wind speed, the solar irradiance, and the load data are available in Reference [31]. These data are applied to the studied distribution networks to imitate the uncertainty effect on HC maximization. The solar irradiance, wind speed, and load profiles for one year are provided in Figures 4-6, respectively. The 8760 hourly data are reduced to relevant 30 scenarios using the backward reduction technique developed by Growe-Kuska et al. for stochastic programming [32]. The obtained scenarios, including loading level $\left(L L_{S}\right)$, wind speed, solar irradiance, and their probabilities $\left(p_{s}\right)$, are provided in Table 1 for each scenario (s). It is well noted that increasing the number of scenarios will increase the 
accuracy of the obtained results; however, conducting the optimization procedure based on 30 scenarios is relevant from the practical perspective [30].

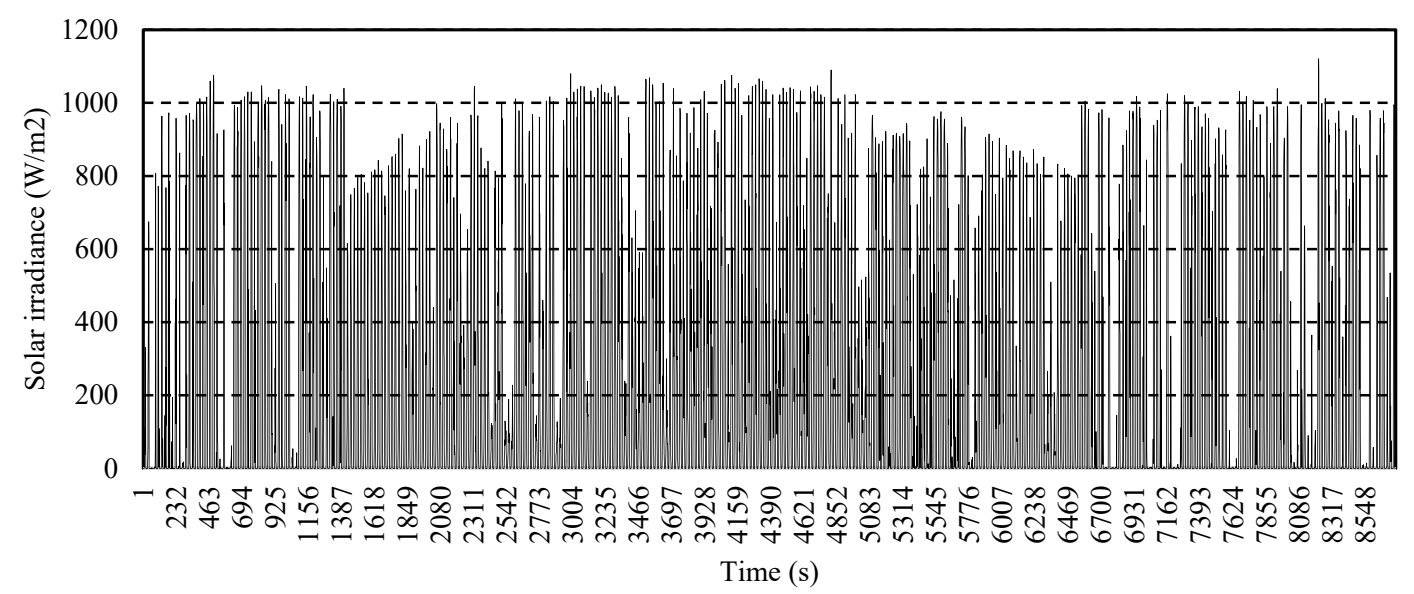

Figure 4. Solar irradiance for one year.

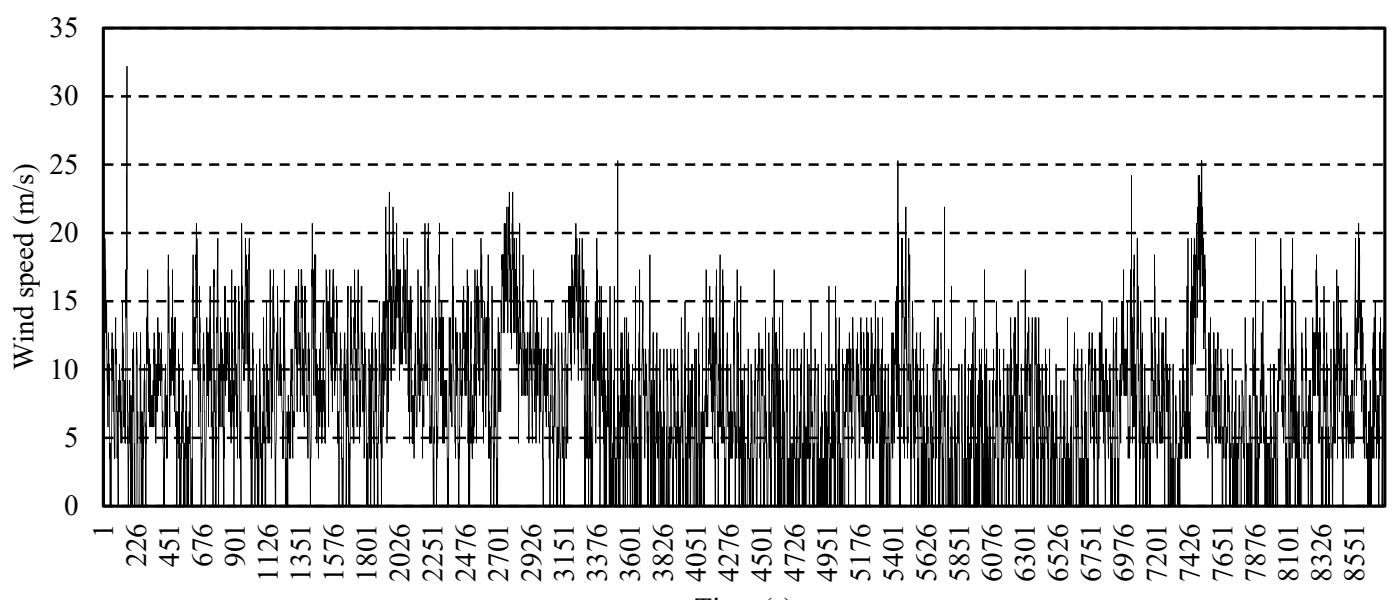

Time (s)

Figure 5. Wind speed for one year.

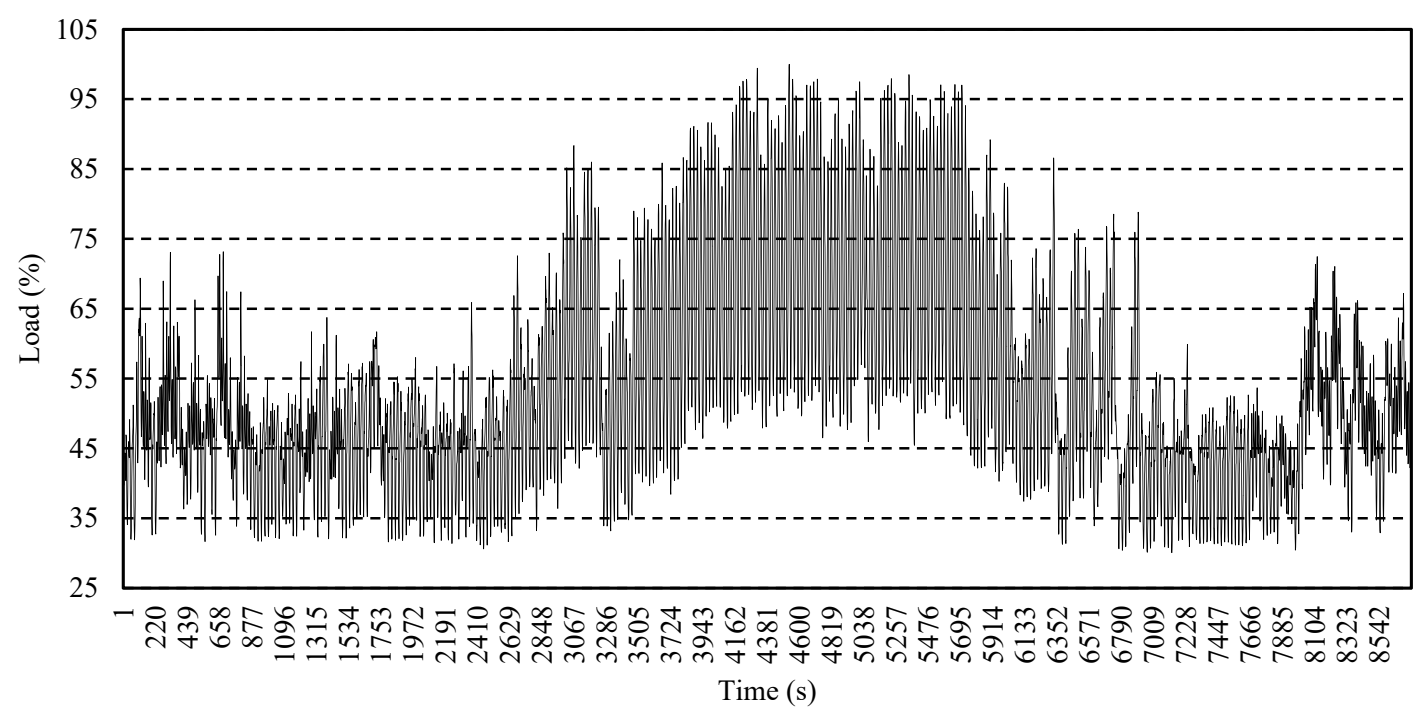

Figure 6. Load profile for one year. 
Table 1. Wind speed, solar irradiance, and load scenarios.

\begin{tabular}{cccccccccc}
\hline $\boldsymbol{s}$ & $\begin{array}{c}\boldsymbol{L} \boldsymbol{L}_{\boldsymbol{s}} \\
\mathbf{( \% )}\end{array}$ & $\begin{array}{c}\boldsymbol{v}_{\boldsymbol{s}} \\
(\mathbf{m} / \mathbf{s})\end{array}$ & $\begin{array}{c}\boldsymbol{G}_{\boldsymbol{s}} \\
\left(\mathbf{W} / \mathbf{m}^{2}\right)\end{array}$ & $p_{\boldsymbol{s}}$ & $\boldsymbol{s}$ & $\begin{array}{c}\mathbf{L}_{\boldsymbol{s}} \\
\mathbf{( \% )}\end{array}$ & $\begin{array}{c}\boldsymbol{v}_{\boldsymbol{s}} \\
(\mathbf{m} / \mathbf{s})\end{array}$ & $\begin{array}{c}\boldsymbol{G}_{\boldsymbol{s}} \\
\left(\mathbf{W} / \mathbf{m}^{2}\right)\end{array}$ & $\boldsymbol{p}_{\boldsymbol{s}}$ \\
\hline 1 & 33.09869 & 0 & 0 & 0.02363 & 16 & 54.70679 & 6.9 & 0 & 0.03664 \\
2 & 33.82429 & 8.1 & 0 & 0.02432 & 17 & 54.97036 & 0 & 0 & 0.03916 \\
3 & 34.79878 & 4.6 & 0 & 0.03139 & 18 & 55.89388 & 11.5 & 455 & 0.02603 \\
4 & 34.85638 & 11.5 & 0 & 0.02454 & 19 & 55.97981 & 0 & 263 & 0.02180 \\
5 & 42.43202 & 3.5 & 0 & 0.04030 & 20 & 58.78500 & 10.4 & 856 & 0.01712 \\
6 & 43.78283 & 10.4 & 0 & 0.05023 & 21 & 59.61178 & 4.6 & 529 & 0.02957 \\
7 & 44.43556 & 5.8 & 448 & 0.01507 & 22 & 60.01654 & 11.5 & 1 & 0.02546 \\
8 & 45.37022 & 8.1 & 0 & 0.09349 & 23 & 65.52149 & 4.6 & 842 & 0.01507 \\
9 & 46.58196 & 9.2 & 900 & 0.04692 & 24 & 69.68230 & 4.6 & 0 & 0.02386 \\
10 & 46.80610 & 12.7 & 0 & 0.03744 & 25 & 70.07522 & 9.2 & 0 & 0.03219 \\
11 & 47.00383 & 0 & 0 & 0.04441 & 26 & 72.52334 & 0 & 0 & 0.01393 \\
12 & 47.66340 & 13.8 & 520 & 0.02420 & 27 & 76.89657 & 10.4 & 935 & 0.03984 \\
13 & 48.58249 & 16.1 & 0 & 0.02877 & 28 & 78.68899 & 6.9 & 0 & 0.05479 \\
14 & 49.39537 & 3.5 & 0 & 0.06975 & 29 & 86.35351 & 13.8 & 363 & 0.01062 \\
15 & 49.46533 & 13.8 & 814 & 0.04384 & 30 & 93.01955 & 10.4 & 478 & 0.01564 \\
\hline
\end{tabular}

\subsection{TOPSIS}

TOPSIS was firstly proposed in the eighth decade of the previous century by Hwang et al. [33]. After that, it has been improved by Yoon [34] in 1987 and by Hwang et al. [35] in 1993. TOPSIS takes place by choosing the preferable alternative (paretosolution) that has the smallest geometric distance from the positive ideal solution and also has the farthest geometric distance from the negative ideal solution. TOPSIS algorithm composed of the following phases:

Phase 1:A matrix $=\left[t_{q l}\right]_{m \times n^{\prime}}$, where $m$ and $n$ denote the number of alternatives and the criteria, respectively. A vector of preset weights $\omega_{l}$ is established for each criterion in which the sum of its weights equals one. After that, a matrix $(N)$ called the 'normalized matrix' is established, where $N=\left[e_{q l}\right]_{m \times n}$, and its elements $e_{q l}$ are obtained using the following equation:

$$
e_{q l}=t_{q l} / \sqrt{\sum_{l=1}^{n} t_{q l}^{2}}
$$

Phase 2:A new matrix $(W N)$ is calculated, whose dimensions are $m \times n$, and its elements $O_{q l}$ are calculated as follows:

$$
O_{q l}=e_{q l} \cdot \omega_{l}
$$

Phase 3:At this phase, the best and the worst alternatives are denoted by the $1 \times n$ vectors: $E$ and $F$, respectively. The elements of $E$ and $F$ are denoted by $D_{l}$ and $G_{l}$, respectively.

$$
\begin{aligned}
& D_{l}=\left\{\left\langle\max _{l} O_{q l} \mid l \in J^{-}\right\rangle,\left\langle\min _{l} O_{q l} \mid l \in J^{+}\right\rangle\right\} \\
& G_{l}=\left\{\left\langle\min _{q} O_{q l} \mid l \in J^{-}\right\rangle,\left\langle\max _{q} O_{q l} \mid l \in J^{+}\right\rangle\right\}
\end{aligned}
$$

where $J^{-}$and $J^{+}$are the negative and positive criteria, respectively.

Phase 4:For each alternative, the least-squares distances between the $q$ th alternative and $D_{l}$ and $G_{l}$ are expressed in Equations (12) and (13), respectively.

$$
d_{q}^{b e s t}=\sqrt{\sum_{l=1}^{n}\left(e_{q l}-D_{l}\right)^{2}}
$$




$$
d_{q}^{\text {worst }}=\sqrt{\sum_{l=1}^{n}\left(e_{q l}-G_{l}\right)^{2}}
$$

where $d_{q}^{\text {best }}$ and $d_{q}^{\text {worst }}$ are the distance of each alternative from the best and the worst elements, respectively.

Phase 5:At this phase, the similarity index for the qth alternative $\left(S I_{q}\right)$ expressed in Equation (12) is calculated to sort the alternatives.

$$
S I_{q}=d_{q}^{\text {worst }} /\left(d_{q}^{\text {best }}+d_{q}^{\text {worst }}\right)
$$

where $S I_{q}$ belongs to the interval $[0,1]$.

Phase 6:Display the best alternative having the highest $S I_{q}$ value.

\subsection{System Performance Indices}

In this work, two performance indices are used to assess the overall operational performance of the studied distribution networks at different scenarios, including the load balancing index $(L B I)$, the aggregated voltage deviation index $(A V D I)$, and the aggregated fast voltage stability index (FVSI).

\subsubsection{Load Balancing Index (LBI)}

The $L B I$ was previously used in many publications to assess the loading carried by each line [36]. The LBI was used many times to obtain a better distribution of currents among the lines of the distribution feeders. The formulation of the LBI is illustrated as follows:

$$
\begin{gathered}
L B I_{b, s}=\left(I_{b, s} / I^{\text {rated }}\right)^{2} \\
L B I_{s}=\sum_{b=1}^{N_{b}} L B I_{b, s}( \\
L B I_{o v}=\sum_{s=1}^{N^{s}} L B I_{s} \cdot p_{s}
\end{gathered}
$$

where $N^{s}$ is the total number of scenarios, and $\left|I_{b, s}\right|$ is the magnitude of the branch current flowing in the $b$ th branch at the sth scenario. $I^{\text {rated }}$ is the maximum line current. $L B I_{b, s}$ is the LBI at the sth scenario for the $b$ th line, $L B I_{S}$ is the aggregated LBI for all lines at the sth scenario, and $L B I_{o v}$ is the overall LBI for all scenarios.

\subsubsection{Aggregate Voltage Deviation Index (AVDI)}

The AVDI was previously employed in many research works like Reference [5] to provide an insight into the voltage deviations from the unity, where the lower AVDI indicates better voltage security at the demand node. The AVDI is formulated as follows:

$$
\begin{aligned}
& A V D I_{s}=\sum_{k=1}^{N^{n o d e}}\left(1-\left|V_{k, s}\right|\right) \\
& A V D I_{o v}=\sum_{s=1}^{N^{s}}\left(A V D I_{s} \cdot p_{s}\right)
\end{aligned}
$$

where $A V D I_{s}$ is the aggregated voltage deviation index at the sth scenario, $\left|V_{k, s}\right|$ is the magnitude of the $k$ th node at the sth scenario, and $A V D I_{v v}$ is the overall aggregated voltage deviation index for all scenarios.

\subsubsection{Fast Voltage Stability Index (FVSI)}

The FVSI was proposed in References $[37,38]$ as a measure for the voltage security at each node. The lower the value of the FVSI, the more voltage security obtained. The fast voltage stability index is formulated as follows:

$$
F V S I_{b, s}=\left|\left(4 Z_{b, s}^{2} Q_{k+1, s}\right) /\left(\left|V_{k+1, s}\right|^{2} x_{b, s}\right)\right|
$$




$$
\begin{gathered}
F V S I_{s}=\sum_{b=1}^{N_{b}} F V S I_{b, s}( \\
F V S I_{o v}=\sum_{s=1}^{N^{s}} F V S I_{s} \\
F V S I_{b, s}<1
\end{gathered}
$$

where $F V S I_{b, s}$ is the FVSI of the $b$ th line at the sth scenario, $Z_{b, s}$ is the impedance of the $b$ th line at the sth scenario, whose reactive component is $x_{b, s}, F V S I_{s}$ is the aggregated FVSI for all distribution system lines at the sth scenario, and $F V S I_{o v}$ is the overall aggregated fast voltage stability index for all scenarios.

\section{Problem Formulation}

In this section, the objective function and the constraints are illustrated in detail.

\subsection{Objective Function}

In this paper, a bilevel multi-objective optimization problem is formulated for HC maximization while considering network losses. The objective function in this work is twofold, including the upper- and the lower-level optimization approaches. On the one hand, the upper-level optimization problem in Equation (28) is formulated as a multiobjective optimization problem to maximize the probabilistic hosting capacity $(\mathrm{PHC})$ of DGs expressed in Equation (25), and also maximize the total power loss reduction $\left(R P_{\text {loss }}\right)$ expressed in Equation (27). On the other hand, the lower-level optimization approach takes place using the DNR mathematical algorithm to choose the appropriate configuration providing a better reduction in the power loss; thus, the objective function at this level is Equation (25). The pseudo-code for the proposed stochastic optimization approach is provided in Algorithm 1.

$$
\begin{gathered}
H C_{s}(\%)=100 \frac{\sum_{u_{W T}} P_{u_{W T}, s}^{D G-W T}+\sum_{u_{P V}} P_{u_{P V}, s}^{D G-P V}}{\sum_{k=1}^{N^{n o d e}} P_{k}^{L}} \\
P H C(\%)=\sum_{s=1}^{N^{s}} P H C_{s} \cdot p_{s} \\
P_{\text {loss }}=\sum_{s=1}^{N^{s}}\left(\sum_{b=1}^{N^{l i n e}}\left(\left|I_{b, s}\right|^{2} \cdot r_{b}\right) \cdot p_{s}\right) \\
R P_{\text {loss }}(\%)=100 \frac{P_{\text {loss }}^{0}-P_{\text {loss }}}{P_{\text {loss }}^{0}} \\
\left\{\begin{array}{l}
\max f_{1}=P H C \\
\max f_{2}=R P_{\text {loss }}
\end{array}\right.
\end{gathered}
$$

where $H C_{s}$ is the $\mathrm{HC}$ at the $s$ th scenario, $P_{\text {loss }}$ is the probabilistic total active loss for all the studied scenarios, and $P_{\text {loss }}^{0}$ is the total power loss at the normal loading conditions.

\subsection{Constraints}

In addition to the constraints of WT, PV DGs rated capacities expressed in Equations (5) and (7) and the FVSI constraint provided in Equation (23). The following operational/planning constraints are applied in the optimization process.

$$
\begin{gathered}
\left|I_{b, s}\right| \leq I^{\text {rated }} \\
V^{\text {min }} \leq\left|V_{k, s}\right| \leq V^{\text {max }} \\
H C_{s} \leq 100 \\
P_{s}^{\text {slack }} \geq 0
\end{gathered}
$$


where $P_{s}^{\text {slack }}$ in the active power delivered by the substation at the sth scenario, and $V^{\text {min }}$ and $V^{\max }$ are the lower and upper nodal voltage limits, respectively.

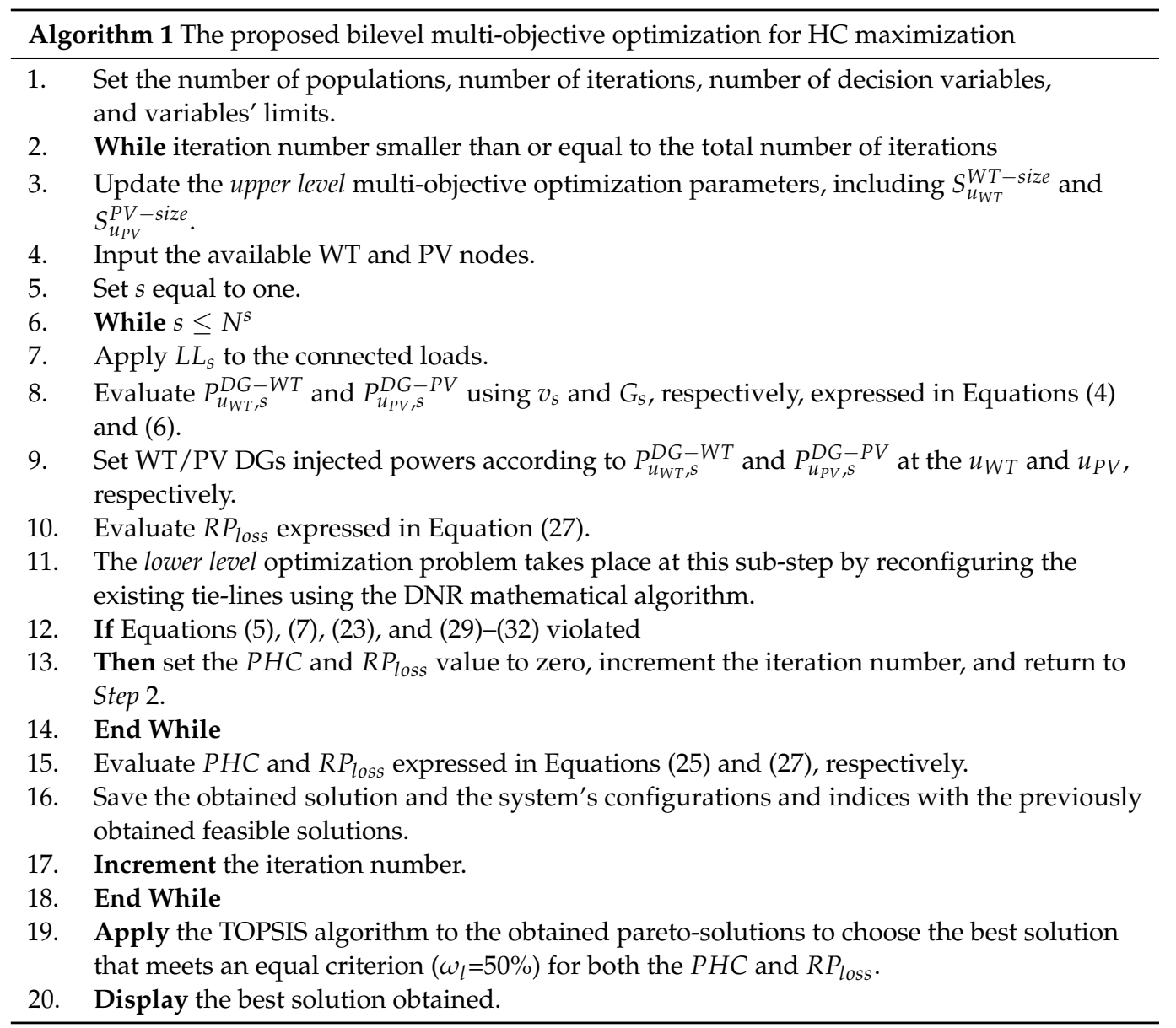

\section{Results and Discussion}

In this work, five distribution networks, 16-, 59-, 69, 83-, and 415- node distribution networks are used [39-42]. The 415-node distribution network is a large distribution network, composed of five instances of the 83-node real distribution network to mimic the complexity of large real distribution networks. The schematic diagrams of the 59- and 83-node distribution networks are provided in Figures 7 and 8. The input data used for the upcoming case study is supplied in Tables 2 and 3. In this work, two multi-objective optimization approaches are employed to solve the upper multi-objective nonlinear optimization problem, including non-dominated sorting genetic algorithm (NSGA-II) [24] and the multi-objective particle swarm optimization (MOPSO) [25]. NSGA-II is one of the most well-known multi-objective optimizers. It was developed by Deb et al. in 2002 as an improvement for the genetic algorithm to handle multi-objective optimization problems via several characteristics in its code, including fast non-dominated sorting and crowded distance estimation. The reader is referred to Reference [24] for more details about this multi-objective optimization algorithm. In the particle swarm optimization algorithm, each solution is known by its position and velocity, where the best solution of the particles at a certain iteration is denoted by pbest, and the global solution obtained till the current iteration is denoted by gbest. A further extension was conducted in Reference [25] to handle multi-objective optimization problems. The reader is referred to Reference [25] for more details about MOPSO. The flowcharts of the NSGA-II and MOPSO are shown in Figures 9 and 10. Furthermore, the DNR mathematical algorithm in Reference [18] used to reconfigure the studied distribution networks in the lower-level optimization problem. 
The following case study is conducted on MATLAB r2018a on a DELL Laptop, its model name is 'Latitude E7450', including an 'Intel ${ }^{\circledR} \mathrm{Core}^{\mathrm{TM}} \mathrm{i} 5^{\prime} \mathrm{CPU}$ at $2.3 \mathrm{GHz}$, and 8 GB RAM.

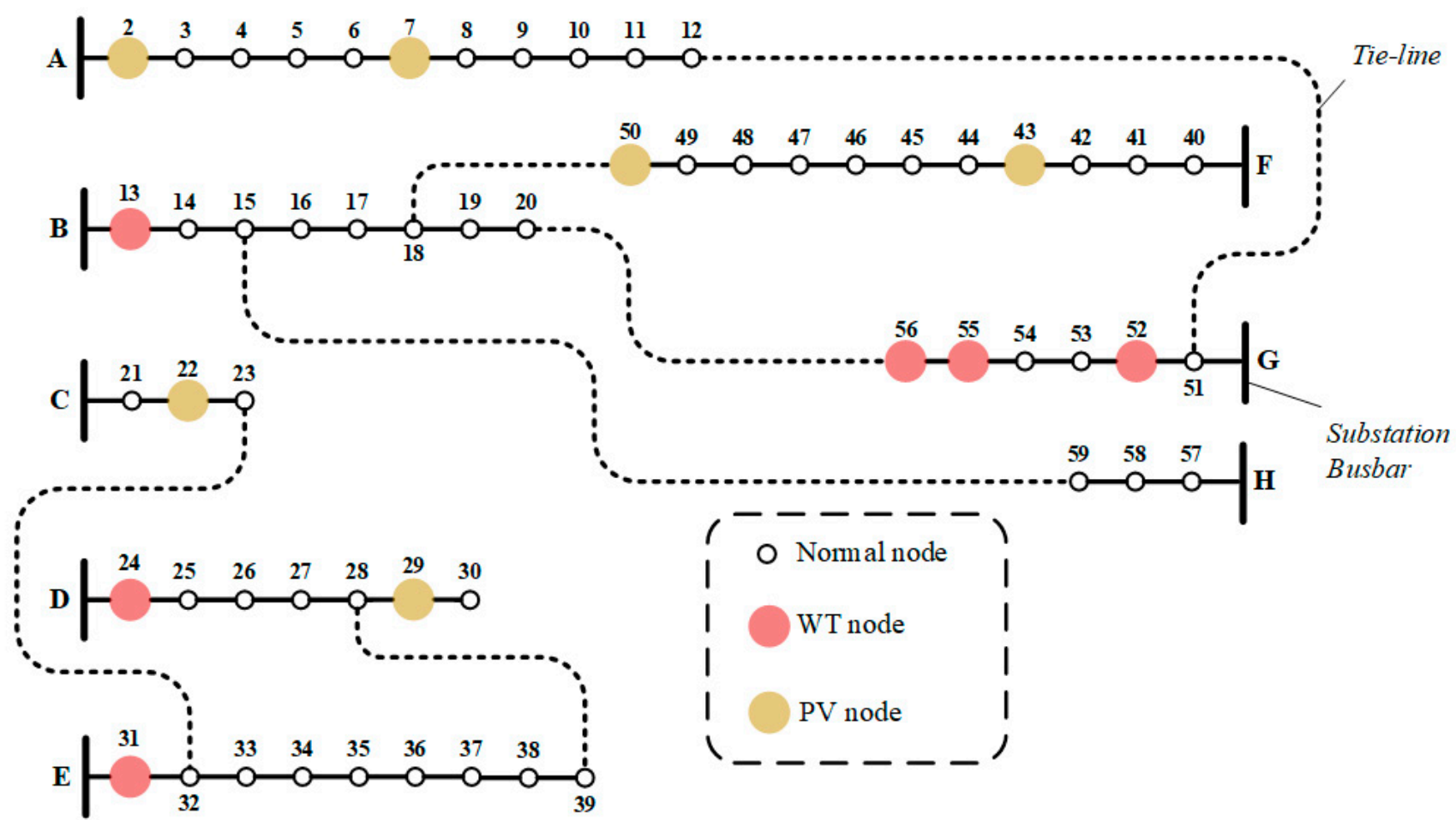

Figure 7. 59-node real distribution network in Cairo.

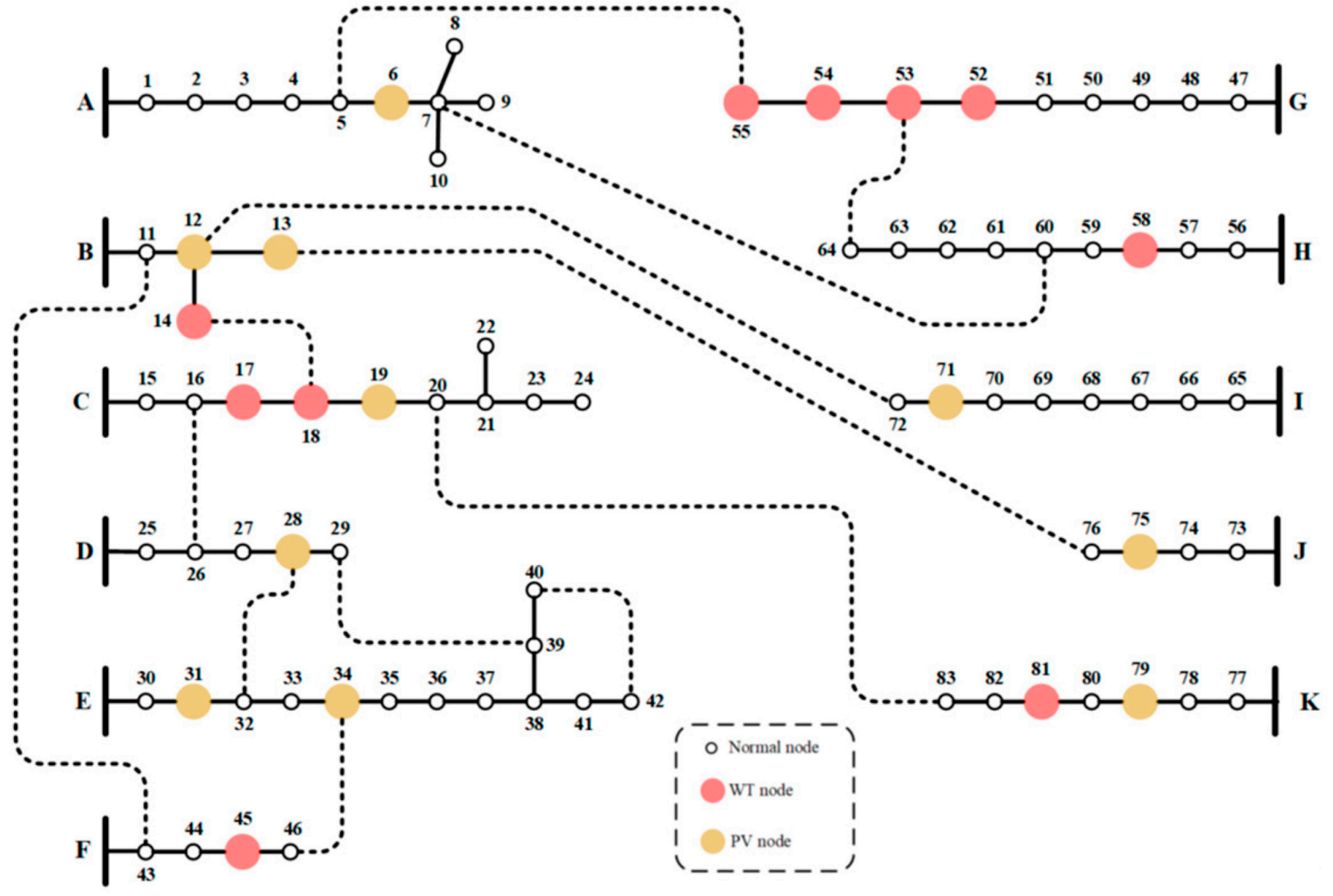

Figure 8. 83-node real distribution network in Taiwan. 


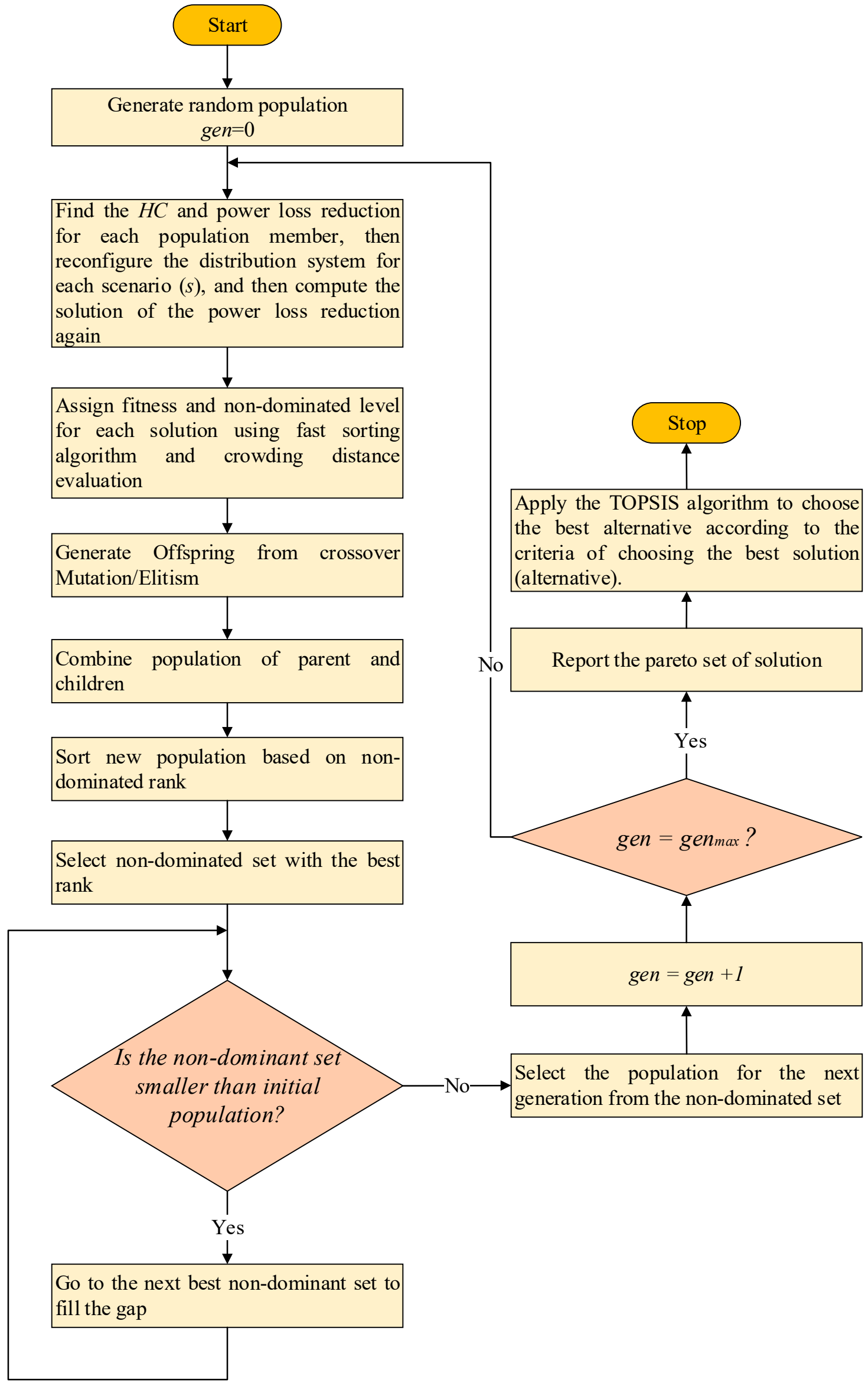

Figure 9. Flowchart of the non-dominated sorting genetic algorithm (NSGA-II) optimization algorithm. 


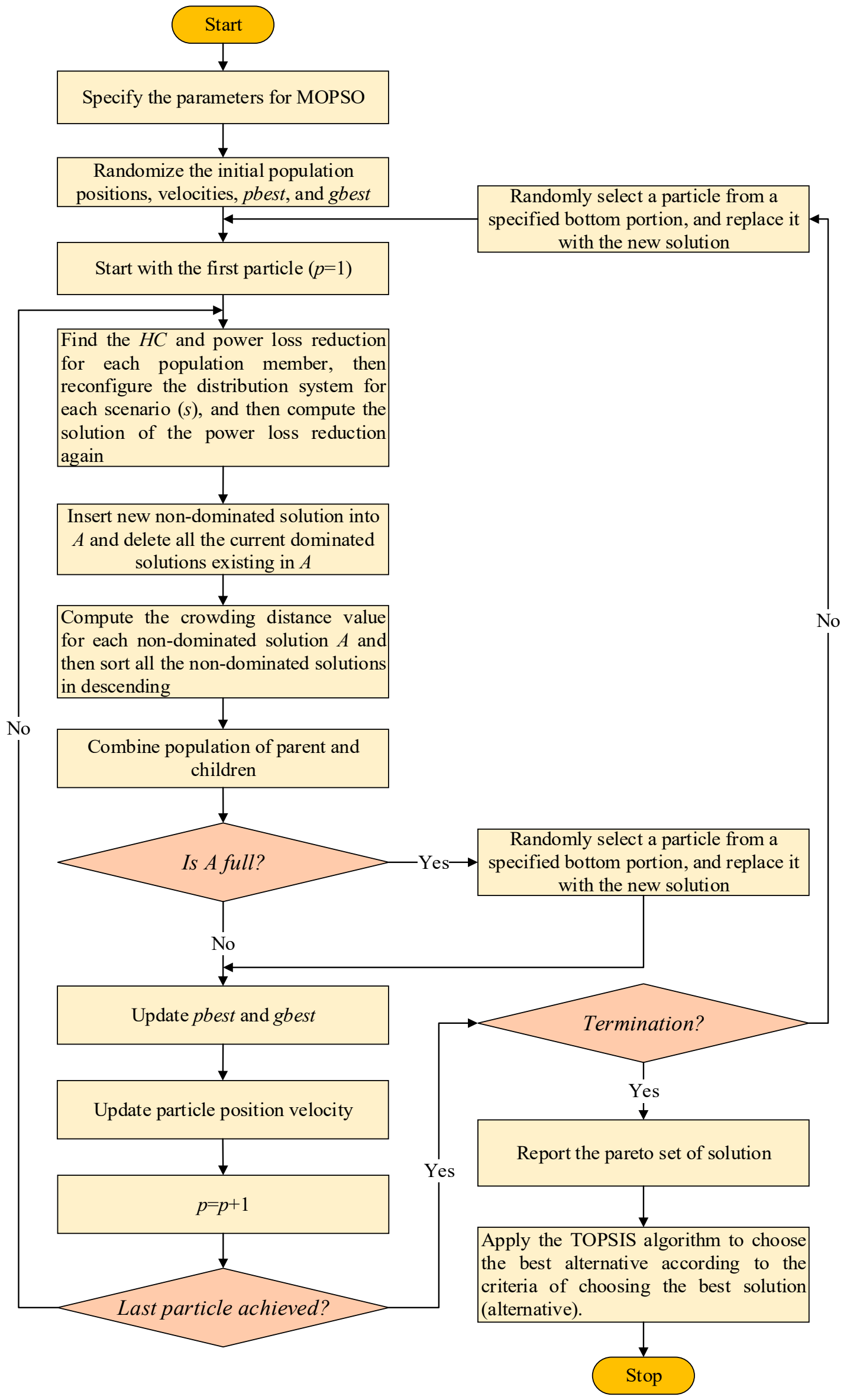

Figure 10. Flowchart of the multi-objective particle swarm optimization (MOPSO) algorithm. 
Table 2. Distribution test networks data.

\begin{tabular}{cccccc}
\hline $\begin{array}{c}\text { Distribution } \\
\text { Network }\end{array}$ & Feeders & $\begin{array}{c}\text { Nodes } \\
\text { Count }\end{array}$ & Lines Count & $\begin{array}{c}\text { Tie-Lines } \\
\text { Count }\end{array}$ & Load (MVA) \\
\hline 16-node & 3 & 13 & 16 & 3 & $28.7+17.3 i$ \\
59-node & 8 & 59 & 64 & 6 & $50.348+21.448 i$ \\
69-node & 1 & 69 & 73 & 5 & $3.80219+2.6946 i$ \\
83-node & 11 & 83 & 96 & 13 & $28.4+20.7 i$ \\
415 -node & 55 & 415 & 480 & 65 & $141.8+103.5 i$ \\
880-node & 7 & 873 & 900 & 27 & $124.9+74.4 i$ \\
\hline
\end{tabular}

Table 3. System input parameters.

\begin{tabular}{cccc}
\hline Parameter & Value & Parameter & Value \\
\hline$v_{\text {cut-in }}(\mathrm{m} / \mathrm{s})$ & 3 & $R_{c}\left(\mathrm{~W} / \mathrm{m}^{2}\right)[29]$ & 150 \\
$v_{\text {cut-out }}(\mathrm{m} / \mathrm{s})$ & 26 & $S_{P V}^{\max }(\mathrm{MW})$ & {$[0,50]$} \\
$v_{\text {rated }}(\mathrm{m} / \mathrm{s})$ & 15 & $I^{\text {rated }}(\mathrm{A})$ & 300 \\
$S_{W T}^{\max }(\mathrm{MW})$ & {$[0,50]$} & $V^{\min }(\mathrm{p} . \mathrm{u})$. & 0.95 \\
$G_{\text {std }}\left(\mathrm{W} / \mathrm{m}^{2}\right)[29]$ & 1000 & $V^{\max }(\mathrm{p} . \mathrm{u})$. & 1.05 \\
\hline
\end{tabular}

In this work, the WT and PV DGs are allocated at a certain set of nodes due to land space limitations. These PV/WT nodes are provided in Table 4 . The PHC is assessed for the 16-, 59-, 69-, 83-, and 415-node distribution networks at different scenarios of wind speeds, solar irradiance, and load uncertainties, as shown in Table 5. The pareto-front of the obtained results for the 83- and 415-node distribution networks are provided in Figures 11 and 12, respectively. The WT and PV DGs sizes in MW at each node using NSGA-II and MOPSO, are provided in Tables 6 and 7, respectively. Besides, the configurations of the 16-, 59-, 69-, 83, and 415-node distribution networks at each scenario are provided in Tables 8-12, respectively. The HC and power loss reduction are provided in Figures 13 and 14, respectively, for the 59-, 83-, and 415-node distribution networks at each scenario. Finally, the voltage profiles at multiple scenarios for the 59-and 83-node distribution networks are provided in Figures 15 and 16, respectively.

Table 4. Candidate wind turbine (WT) and photovoltaic (PV) nodes.

\begin{tabular}{ccc}
\hline System & WT Nodes & PV Nodes \\
\hline 16-node & $4,5,16$ & $8,9,12$ \\
\hline 59-node & $13,24,31,52,55,56$ & $2,7,22,29,43,50$ \\
\hline 69-node & $7,8,16,17,18,37,40,54$ & $11,12,21,38,39,48,50,53$ \\
\hline 83-node & $14,17,18,45,51,52,53,54,58,81$ & $6,12,13,19,28,31,34,71,75,79$ \\
\hline & $24,27,28,62,63,64,68,91,118,121$, & $16,22,23,29,38,41,44,55,61,81,85,89,110$, \\
& $122,156,157,158,162,185,212,215,216,243$, & $116,117,123,132,135,138,149,155,175,179$, \\
& $249,250,251,252,256,279,305,306,309,310$, & $183,204,210,211,217,226,229,232,269,273$, \\
& $326,337,343,344,345,346,350,373,399,400$, & $277,298,304,311,320,323,363,367,371,392$, \\
& $403,404,420,431,437,438,439,440,444,467$ & $398,405,414,417,457,461,465$ \\
\hline & $13,18,43,53,54,59,89,90,101,122,137,140$, & $11,19,20,33,40,52,70,80,85,87,94,95,111$, \\
& $144,146,151,171,174,196,214,219,244,254$, & $112,138,139,152,153,172,173,185,186,212$, \\
& $255,260,290,291,302,323,338,341,345,350$, & $220,221,234,241,253,271,281,286,288,295$, \\
& $351,362,383,389,393,398,399,410,416,420$, & $296,312,313,339,340,348,355,356,372,373$, \\
& $440,455,458,464,465,470,498,500,501,512$, & $387,388,396,403,414,415,423,429,430,456$, \\
& $533,548,551,555,558,560,561,593,599,603$, & $457,463,481,491,496,505,506,522,523,549$, \\
& $606,608,609,620,626,630,633,650,665,668$, & $550,565,566,582,583,597,598,613,624,625$, \\
& $670,672,673,705,720,723,727,730,732,733$, & $639,640,666,667,677,678,694,695,721,722$, \\
& $765,771,775,778,780,781,792,798,802,805$, & $737,738,754,755,769,770,785,796,797,811$, \\
& $822,837,840,842,848,852,855,872$ & $812,838,839,846,847,861,862$
\end{tabular}


Table 5. Results for the studied distribution networks.

\begin{tabular}{|c|c|c|c|c|}
\hline System & Index & Initial & NSGA-II & MOPSO \\
\hline \multirow{8}{*}{ 16-node } & PHC (\%) & - & 17.9159 & 13.6892 \\
\hline & $R P_{\text {loss }}(\%)$ & 0 & 79.5223 & 79.9342 \\
\hline & $L B I_{o v}$ & 1.1432 & 0.7997 & 0.7858 \\
\hline & $A V D I_{o v}$ & 0.1111 & 0.0750 & 0.0834 \\
\hline & $F V S I_{o v}$ & 0.0539 & 0.0485 & 0.0452 \\
\hline & $\min \left|V_{k, s}\right|$ (p.u.) & 0.9715 & 0.9778 & 0.9778 \\
\hline & $\max \left|V_{k, s}\right|$ (p.u.) & 1 & 1.0039 & 1.0056 \\
\hline & Time $(\mathrm{h})$ & - & 3.3254 & 5.7375 \\
\hline \multirow{8}{*}{ 59-node } & PHC (\%) & - & 18.087 & 14.05 \\
\hline & $R P_{\text {loss }}(\%)$ & 0 & 83.3078 & 81.8076 \\
\hline & $L B I_{o v}$ & 3.6844 & 2.4137 & 2.9178 \\
\hline & $A V D I_{o v}$ & 0.1407 & 0.0844 & 0.0847 \\
\hline & $F V S I_{o v}$ & 0.0666 & 0.0549 & 0.0523 \\
\hline & $\min \left|V_{k, s}\right|$ (p.u.) & 0.9874 & 0.9944 & 0.9931 \\
\hline & $\max \left|V_{k, s}\right|$ (p.u.) & 1 & 1.0004 & 1.0029 \\
\hline & Time (h) & - & 5.3130 & 6.2609 \\
\hline \multirow{8}{*}{ 69-node } & PHC (\%) & - & 17.0725 & 18.6119 \\
\hline & $R P_{\text {loss }}(\%)$ & 0 & 89.1300 & 87.9905 \\
\hline & $L B I_{o v}$ & 1.2040 & 0.5814 & 0.6098 \\
\hline & $A V D I_{o v}$ & 0.9485 & 0.3513 & 0.3198 \\
\hline & $F V S I_{o v}$ & 0.4003 & 0.2609 & 0.2681 \\
\hline & $\min \left|V_{k, s}\right|$ (p.u.) & 0.9161 & 0.9554 & 0.9536 \\
\hline & $\max \left|V_{k, s}\right|$ (p.u.) & 1 & 1.0036 & 1.0140 \\
\hline & Time (h) & - & 1.5584 & 0.9694 \\
\hline \multirow{8}{*}{ 83-node } & PHC (\%) & - & 17.9875 & 17.6474 \\
\hline & $R P_{\text {loss }}(\%)$ & 0 & 80.7985 & 80.3160 \\
\hline & $L B I_{o v}$ & 4.3873 & 3.0877 & 3.0516 \\
\hline & $A V D I_{o v}$ & 1.3348 & 1.0697 & 1.1120 \\
\hline & $F V S I_{o v}$ & 0.6173 & 0.5900 & 0.6005 \\
\hline & $\min \left|V_{k, s}\right|$ (p.u.) & 0.9339 & 0.9601 & 0.9589 \\
\hline & $\max \left|V_{k, s}\right|$ (p.u.) & 1 & 1 & 1 \\
\hline & Time $(\mathrm{h})$ & - & 9.1571 & 8.8585 \\
\hline \multirow{8}{*}{ 415-node } & PHC (\%) & - & 17.7173 & 17.5299 \\
\hline & $R P_{\text {loss }}(\%)$ & 0 & 74.5320 & 79.2044 \\
\hline & $L B I_{o v}$ & 21.9362 & 19.3506 & 16.4757 \\
\hline & $A V D I_{o v}$ & 6.6732 & 6.0285 & 5.3153 \\
\hline & $F V S I_{o v}$ & 3.0863 & 3.0565 & 2.9472 \\
\hline & $\min \left|V_{k, s}\right|$ (p.u.) & 0.9339 & 0.9511 & 0.9566 \\
\hline & $\max \left|V_{k, s}\right|$ (p.u.) & 1 & 1.0066 & 1.0040 \\
\hline & Time (h) & - & 74.2285 & 74.3252 \\
\hline \multirow{8}{*}{ 880-node } & PHC (\%) & - & 18.0692 & 18.0224 \\
\hline & $R P_{\text {loss }}(\%)$ & 0 & 93.5010 & 93.4466 \\
\hline & $L B I_{o v}$ & 4.1141 & 1.2709 & 1.3006 \\
\hline & $A V D I_{o v}$ & 6.0015 & 1.7829 & 1.7772 \\
\hline & $F V S I_{o v}$ & 0.2474 & 0.1490 & 0.1439 \\
\hline & $\min \left|V_{k, s}\right|$ (p.u.) & 0.9593 & 0.9935 & 0.9936 \\
\hline & $\max \left|V_{k, s}\right|$ (p.u.) & 1 & 1 & 1.0004 \\
\hline & Time $(\mathrm{h})$ & - & 105.7501 & 104.7001 \\
\hline
\end{tabular}




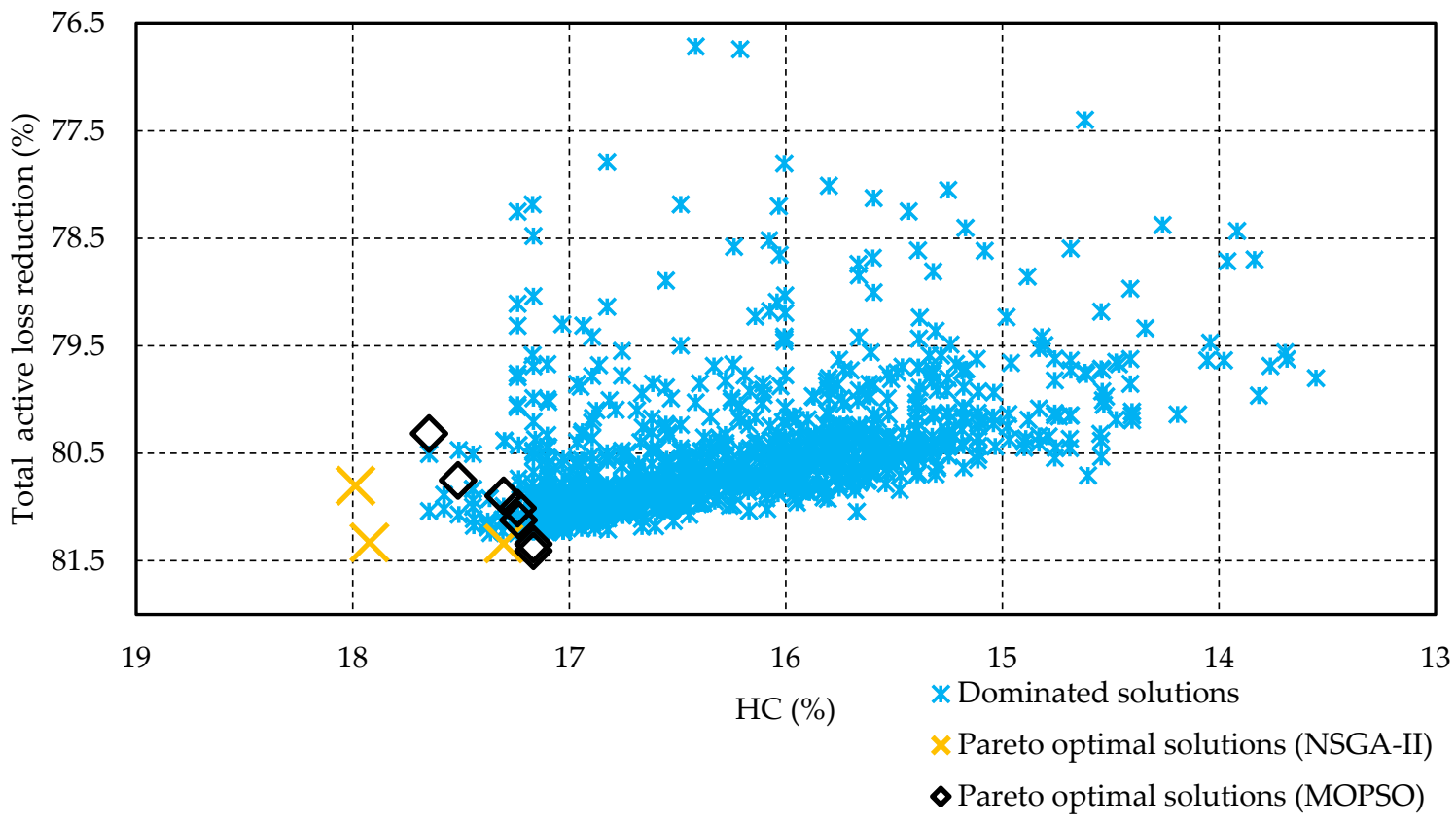

Figure 11. Pareto-front for the 83-node distribution network using NSGA-II and MOPSO.

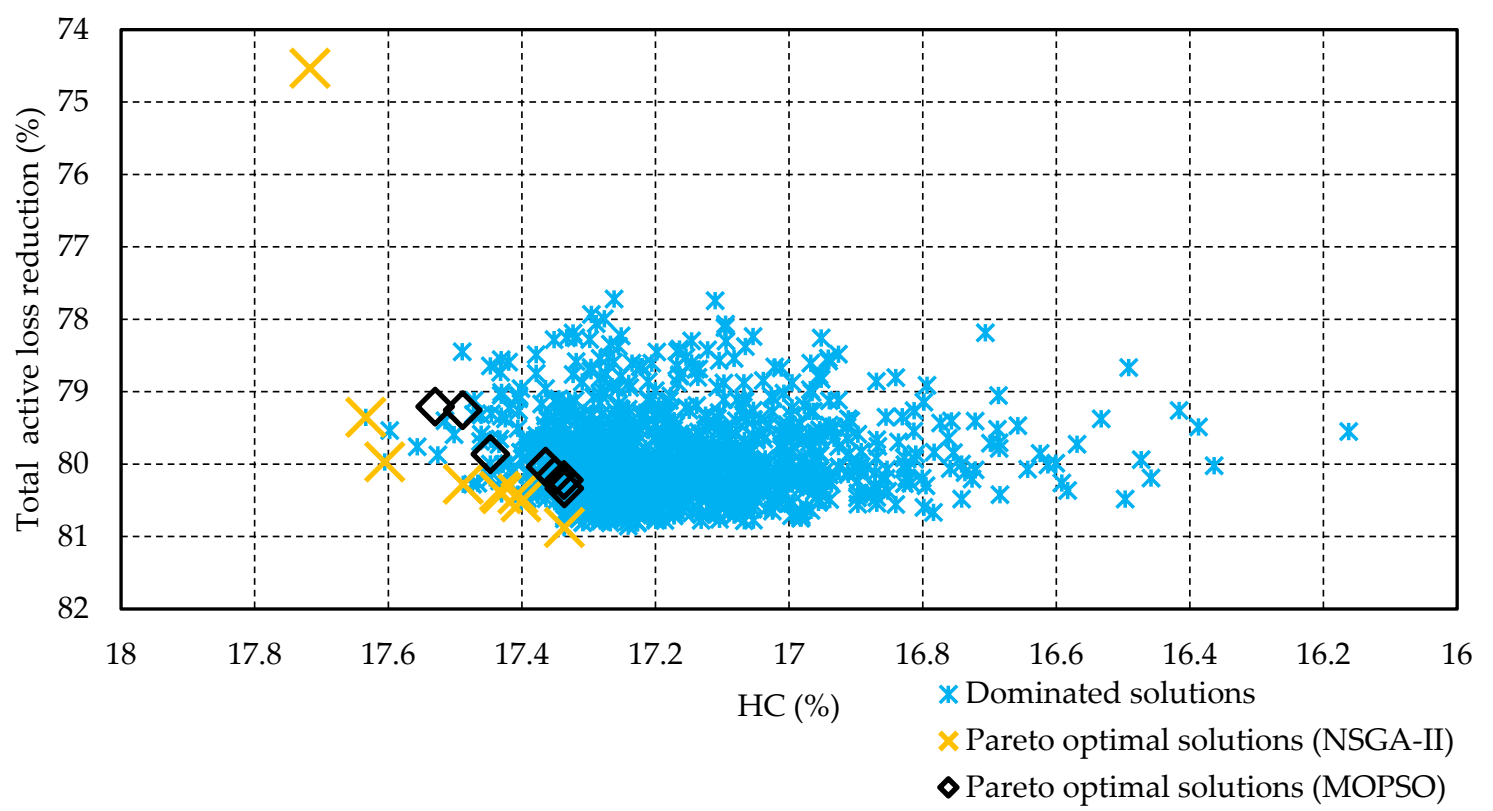

Figure 12. Pareto-front for the 415-node distribution network using NSGA-II and MOPSO.

Table 6. WT and PV distributed generations (DGs) sizes in MW at each node using NSGA-II.

\begin{tabular}{cccccccc}
\hline $\begin{array}{c}\text { WT } \\
\text { Node }\end{array}$ & WT Size & $\begin{array}{c}\text { WT } \\
\text { Node }\end{array}$ & WT Size & PV Node & PV Size & PV Node & PV Size \\
\hline \multicolumn{7}{c}{} \\
\hline 4 & 2 & 5 & 1 & 8 & 2.8 & 9 & 3 \\
16 & 5.9 & - & - & 12 & 1.8 & - & - \\
\hline
\end{tabular}


Table 6. Count.

\begin{tabular}{|c|c|c|c|c|c|c|c|}
\hline $\begin{array}{c}\text { WT } \\
\text { Node }\end{array}$ & WT Size & $\begin{array}{c}\text { WT } \\
\text { Node }\end{array}$ & WT Size & PV Node & PV Size & PV Node & PV Size \\
\hline \multicolumn{8}{|c|}{ 59-node distribution network } \\
\hline 13 & 1.7 & 52 & 2.1 & 2 & 2.4 & 29 & 1.4 \\
\hline 24 & 5.5 & 55 & 2.8 & 7 & 2.8 & 43 & 2.2 \\
\hline 31 & 1.7 & 56 & 2.3 & 22 & 2.3 & 50 & 1.7 \\
\hline \multicolumn{8}{|c|}{ 69-node distribution network } \\
\hline 7 & 0.1 & 18 & 0.1 & 11 & 0 & 39 & 0.2 \\
\hline 8 & 0.2 & 37 & 0.2 & 12 & 0.2 & 48 & 0.2 \\
\hline 16 & 0.1 & 40 & 0.1 & 21 & 0.2 & 50 & 0 \\
\hline 17 & 0.1 & 54 & 0.1 & 38 & 0.2 & 53 & 0.2 \\
\hline \multicolumn{8}{|c|}{ 83-node distribution network } \\
\hline 14 & 0.8 & 52 & 0.4 & 6 & 0.8 & 31 & 0.7 \\
\hline 17 & 0.7 & 53 & 0.7 & 12 & 0.5 & 34 & 1 \\
\hline 18 & 1 & 54 & 0.7 & 13 & 0.7 & 71 & 1.1 \\
\hline 45 & 1.1 & 58 & 0.9 & 19 & 0.2 & 75 & 0.5 \\
\hline 51 & 0.9 & 81 & 1.8 & 28 & 0.7 & 79 & 1 \\
\hline \multicolumn{8}{|c|}{ 415-node distribution network } \\
\hline 24 & 0 & 279 & 3 & 16 & 0 & 210 & 0.2 \\
\hline 27 & 0 & 305 & 2 & 22 & 0 & 211 & 0 \\
\hline 28 & 0.9 & 306 & 0 & 23 & 0.3 & 217 & 1.8 \\
\hline 62 & 0 & 309 & 3.3 & 29 & 0 & 226 & 2 \\
\hline 63 & 2.2 & 310 & 2 & 38 & 0 & 229 & 0 \\
\hline 64 & 0.5 & 326 & 0 & 41 & 3.3 & 232 & 1.1 \\
\hline 68 & 0 & 337 & 0 & 44 & 2 & 269 & 0 \\
\hline 91 & 0 & 343 & 1.5 & 55 & 0 & 273 & 0 \\
\hline 118 & 3.5 & 344 & 0 & 61 & 2.2 & 277 & 0.8 \\
\hline 121 & 2.8 & 345 & 3.3 & 81 & 0 & 298 & 0 \\
\hline 122 & 2.8 & 346 & 3.5 & 85 & 1.7 & 304 & 0 \\
\hline 156 & 0.9 & 350 & 0 & 89 & 0 & 311 & 1.5 \\
\hline 157 & 0 & 373 & 0 & 110 & 2.8 & 320 & 2.9 \\
\hline 158 & 2 & 399 & 0 & 116 & 0 & 323 & 0 \\
\hline 162 & 1.9 & 400 & 0 & 117 & 0 & 363 & 0 \\
\hline 185 & 0 & 403 & 0 & 123 & 0 & 367 & 0 \\
\hline 212 & 0 & 404 & 1.7 & 132 & 0 & 371 & 0 \\
\hline 215 & 0 & 420 & 3.6 & 135 & 0 & 392 & 0 \\
\hline 216 & 0 & 431 & 0 & 138 & 0 & 398 & 0.4 \\
\hline 243 & 0 & 437 & 0 & 149 & 0 & 405 & 1.2 \\
\hline 249 & 0 & 438 & 0 & 155 & 0 & 414 & 1.7 \\
\hline 250 & 0 & 439 & 0 & 175 & 0 & 417 & 0 \\
\hline 251 & 0 & 440 & 0 & 179 & 0 & 457 & 1.9 \\
\hline 252 & 0 & 444 & 0 & 183 & 2.1 & 461 & 2.5 \\
\hline 256 & 0 & 467 & 2.8 & 204 & 0 & 465 & 3.3 \\
\hline
\end{tabular}

Table 7. WT and PV DGs sizes in MW at each node using MOPSO.

\begin{tabular}{cccccccc}
\hline $\begin{array}{c}\text { WT } \\
\text { Node }\end{array}$ & WT Size & $\begin{array}{c}\text { WT } \\
\text { Node }\end{array}$ & WT Size & PV Node & PV Size & PV Node & PV Size \\
\hline \multicolumn{7}{c}{ 16-node distribution network } \\
\hline 4 & 1 & 5 & 1 & 8 & 4.2 & 9 & 4.3 \\
16 & 1 & - & - & 12 & 4.7 & - & - \\
\hline
\end{tabular}


Table 7. Count.

\begin{tabular}{|c|c|c|c|c|c|c|c|}
\hline $\begin{array}{c}\text { WT } \\
\text { Node }\end{array}$ & WT Size & $\begin{array}{c}\text { WT } \\
\text { Node }\end{array}$ & WT Size & PV Node & PV Size & PV Node & PV Size \\
\hline \multicolumn{8}{|c|}{ 59-node distribution network } \\
\hline 13 & 1 & 52 & 1 & 2 & 2.1 & 29 & 1 \\
\hline 24 & 1 & 55 & 1 & 7 & 4.4 & 43 & 0 \\
\hline 31 & 1 & 56 & 1 & 22 & 2.9 & 50 & 12.2 \\
\hline \multicolumn{8}{|c|}{ 69-node distribution network } \\
\hline 7 & 0 & 18 & 0.1 & 11 & 0 & 39 & 0.3 \\
\hline 8 & 0.3 & 37 & 0 & 12 & 0.3 & 48 & 0 \\
\hline 16 & 0.4 & 40 & 0 & 21 & 0.3 & 50 & 0 \\
\hline 17 & 0 & 54 & 0.5 & 38 & 0 & 53 & 0 \\
\hline \multicolumn{8}{|c|}{ 83-node distribution network } \\
\hline 14 & 1 & 52 & 0.9 & 6 & 0.7 & 31 & 0.6 \\
\hline 17 & 0.7 & 53 & 0.8 & 12 & 1.4 & 34 & 0 \\
\hline 18 & 0.5 & 54 & 0.9 & 13 & 0.3 & 71 & 0.7 \\
\hline 45 & 0.6 & 58 & 1 & 19 & 1.7 & 75 & 0.5 \\
\hline 51 & 1 & 81 & 1 & 28 & 0.8 & 79 & 1.2 \\
\hline \multicolumn{8}{|c|}{ 415-node distribution network } \\
\hline 24 & 0 & 279 & 3 & 16 & 0 & 210 & 0.8 \\
\hline 27 & 0 & 305 & 2 & 22 & 0 & 211 & 0 \\
\hline 28 & 0.9 & 306 & 0 & 23 & 0 & 217 & 2.6 \\
\hline 62 & 0 & 309 & 3.3 & 29 & 0.4 & 226 & 0.7 \\
\hline 63 & 2.2 & 310 & 2 & 38 & 0 & 229 & 0 \\
\hline 64 & 0.5 & 326 & 0 & 41 & 0 & 232 & 2.5 \\
\hline 68 & 0 & 337 & 0 & 44 & 0.3 & 269 & 2.5 \\
\hline 91 & 0 & 343 & 1.5 & 55 & 1.7 & 273 & 0 \\
\hline 118 & 3.5 & 344 & 0 & 61 & 0 & 277 & 0 \\
\hline 121 & 2.8 & 345 & 3.3 & 81 & 0 & 298 & 0 \\
\hline 122 & 2.8 & 346 & 3.5 & 85 & 0.5 & 304 & 2.6 \\
\hline 156 & 0.9 & 350 & 0 & 89 & 1.6 & 311 & 0 \\
\hline 157 & 0 & 373 & 0 & 110 & 2.3 & 320 & 1.9 \\
\hline 158 & 2 & 399 & 0 & 116 & 0.1 & 323 & 0.1 \\
\hline 162 & 1.9 & 400 & 0 & 117 & 2.3 & 363 & 2.4 \\
\hline 185 & 0 & 403 & 0 & 123 & 0 & 367 & 0 \\
\hline 212 & 0 & 404 & 1.7 & 132 & 1.6 & 371 & 0.4 \\
\hline 215 & 0 & 420 & 3.6 & 135 & 0 & 392 & 0 \\
\hline 216 & 0 & 431 & 0 & 138 & 2.6 & 398 & 0 \\
\hline 243 & 0 & 437 & 0 & 149 & 2.6 & 405 & 0 \\
\hline 249 & 0 & 438 & 0 & 155 & 0 & 414 & 1.2 \\
\hline 250 & 0 & 439 & 0 & 175 & 0.9 & 417 & 0.5 \\
\hline 251 & 0 & 440 & 0 & 179 & 2.3 & 457 & 0 \\
\hline 252 & 0 & 444 & 0 & 183 & 1.1 & 461 & 2 \\
\hline 256 & 0 & 467 & 2.8 & 204 & 1.5 & 465 & 0 \\
\hline
\end{tabular}

Table 8. The 16-node distribution network configurations at multiple scenarios.

\begin{tabular}{ccc}
\hline \multirow{2}{*}{$s$} & \multicolumn{2}{c}{ Configuration (Tie-Lines) } \\
\cline { 2 - 3 } & NSGA-II & MOPSO \\
\hline 1 & $7,8,16$ & \\
\hline 13 & $3,7,8$ & $7,8,16$ \\
17 & $7,8,16$ & \\
\hline 29 & $4,7,8$ & \\
\hline
\end{tabular}


Table 9. The 59-node distribution network configurations at multiple scenarios.

\begin{tabular}{ccc}
\hline \multirow{2}{*}{$s$} & \multicolumn{2}{c}{ Configuration (Tie-Lines) } \\
\cline { 2 - 3 } & NSGA-II & MOPSO \\
\hline 1 & $7,18,46,60,63,64$ & $7,19,46,60,63,64$ \\
\hline 5 & $7,17,47,60,63,64$ & \\
\hline 13 & $7,17,37,47,60,63$ & $7,18,46,60,63,64$ \\
\hline 29 & $7,17,38,48,60,63$ & \\
\hline 17 & $7,18,38,46,60,63$ & $7,18,38,46,60,63$ \\
\hline
\end{tabular}

Table 10. The 69-node distribution network configurations at multiple scenarios.

\begin{tabular}{ccc}
\hline \multirow{2}{*}{$s$} & \multicolumn{2}{c}{ Configuration (Tie-Lines) } \\
\cline { 2 - 3 } & NSGA-II & MOPSO \\
\hline 1 & $14,47,50,69,70$ & $14,46,50,69,70$ \\
\hline 5 & $14,44,50,69,70$ & $14,18,45,50,69$ \\
\hline 13 & $13,44,50,69,70$ & $14,20,46,50,69$ \\
\hline 17 & $14,45,50,69,70$ & $13,20,45,50,69$ \\
\hline 29 & $13,46,50,69,70$ & $12,13,47,50,69$ \\
\hline
\end{tabular}

Table 11. The 83-node distribution network configurations at multiple scenarios.

\begin{tabular}{|c|c|c|}
\hline \multirow{2}{*}{$s$} & \multicolumn{2}{|c|}{ Configuration (Tie-Lines) } \\
\hline & NSGA-II & MOPSO \\
\hline 1 & $6,12,33,38,41,54,60,71,82,85,88,89,91$ & $6,33,41,54,60,71,82,85,87,88,89,91,92$ \\
\hline 5 & $6,33,38,41,54,60,71,82,85,87,88,89,91$ & $6,33,41,52,60,71,82,85,87,88,89,91,92$ \\
\hline 13 & $6,33,41,53,60,71,78,85,87,88,89,91,92$ & $6,33,41,52,53,71,85,87,88,89,90,91,92$ \\
\hline 17 & $6,32,41,53,60,71,81,85,87,88,89,91,92$ & $6,33,41,53,63,71,85,87,88,89,90,91,92$ \\
\hline 29 & $6,32,41,54,60,71,82,85,87,88,89,91,92$ & $6,33,38,41,53,61,71,81,85,87,88,89,91$ \\
\hline
\end{tabular}

Table 12. The 415-node distribution network configurations at multiple scenarios.

\begin{tabular}{|c|c|c|}
\hline \multirow{2}{*}{$s$} & \multicolumn{2}{|c|}{ Configuration (Tie-Lines) } \\
\hline & NSGA-II & MOPSO \\
\hline 1 & $\begin{array}{c}6,54,142,143,154,164,220,255,302,320,330, \\
336,338,417,418,419,420,421,422,423,424, \\
425,426,427,428,430,432,433,434,436,437, \\
438,439,442,443,444,445,446,447,448,449, \\
450,451,452,453,456,458,459,460,462,463, \\
464,465,466,469,470,471,472,473,474,475, \\
476,477,478,479\end{array}$ & $\begin{array}{c}6,33,38,41,54,61,71,82,89,116,121,124, \\
144,154,165,172,199,204,207,219,226, \\
237,248,255,282,287,290,310,320,331, \\
338,344,365,370,373,385,392,403,414, \\
417,419,420,421,423,428,430,432,433, \\
434,436,443,445,446,447,449,454,456, \\
458,459,460,462,469,000,000,000\end{array}$ \\
\hline 5 & $\begin{array}{c}6,54,141,143,154,164,220,255,301,302,320, \\
330,336,338,417,418,419,420,421,422,423, \\
424,425,426,427,428,430,432,433,434,436, \\
437,438,439,442,443,444,445,446,447,448, \\
449,450,451,452,453,456,458,459,460,462, \\
463,464,465,469,470,471,472,473,474,475, \\
476,477,478,479\end{array}$ & $\begin{array}{c}6,33,38,41,54,61,71,82,89,116,121,124, \\
144,154,165,172,199,204,207,219,226, \\
237,248,255,261,282,287,290,310,317, \\
331,338,344,365,370,373,385,392,403, \\
414,417,419,420,421,423,428,430,432, \\
433,434,436,443,445,446,447,449,454, \\
456,459,460,462,469,000,000,000\end{array}$ \\
\hline
\end{tabular}


Table 12. Count.

\begin{tabular}{|c|c|c|}
\hline \multirow{2}{*}{$s$} & \multicolumn{2}{|c|}{ Configuration (Tie-Lines) } \\
\hline & NSGA-II & MOPSO \\
\hline 13 & $\begin{array}{c}52,54,140,143,151,164,172,220,255,301, \\
302,320,330,338,417,418,419,420,421,422, \\
423,424,425,426,428,430,432,433,434,436, \\
437,438,439,443,444,445,446,447,448,449, \\
450,451,452,453,456,458,459,460,462,463, \\
464,465,467,469,470,471,472,473,474,475, \\
476,477,478,479\end{array}$ & $\begin{array}{c}6,33,38,41,53,61,71,82,89,116,121,124, \\
144,154,165,172,199,204,207,219,226, \\
237,248,255,261,282,287,290,310,317, \\
331,338,344,365,370,373,384,392,403, \\
414,417,419,420,421,423,428,430,432, \\
433,434,436,443,445,446,447,449,454, \\
456,459,460,462,469,000,000,000\end{array}$ \\
\hline 17 & $\begin{array}{c}52,54,141,143,151,164,172,220,255,287, \\
301,302,320,330,338,417,418,419,420,421, \\
422,423,424,425,426,428,430,432,433,434, \\
436,437,438,439,443,444,445,446,447,448, \\
449,450,451,452,453,456,458,459,460,462, \\
464,465,467,469,470,471,472,473,474, \\
475,476,477,478,479\end{array}$ & $\begin{array}{c}6,33,38,41,53,61,71,82,89,116,121,124, \\
144,154,165,172,199,204,207,219,226, \\
237,248,255,261,262,282,287,290,310, \\
319,331,338,344,365,370,373,385,392, \\
403,414,417,419,420,421,423,428,430, \\
432,433,434,436,443,445,446,447,449, \\
454,456,460,462,469,000,000,000\end{array}$ \\
\hline 29 & $\begin{array}{c}6,12,33,38,41,54,61,71,82,89,95,116,121 \\
124,137,144,152,165,172,178,199,204 \\
207,220,227,237,248,255,261,282,287 \\
290,310,320,331,338,344,365,370,373 \\
386,393,403,414,417,420,421,423,430 \\
433,434,436,443,446,447,449,454,456 \\
459,460,462,469,472,000,000\end{array}$ & $\begin{array}{c}6,33,38,41,54,61,71,82,89,116,121,124, \\
137,144,154,165,172,199,204,207,219, \\
226,237,248,255,261,282,287,290,310, \\
317,331,338,344,365,370,373,385,392, \\
403,414,417,419,420,421,423,430,432, \\
433,434,436,443,445,446,447,449,454, \\
456,459,460,462,469,000,000,000\end{array}$ \\
\hline
\end{tabular}

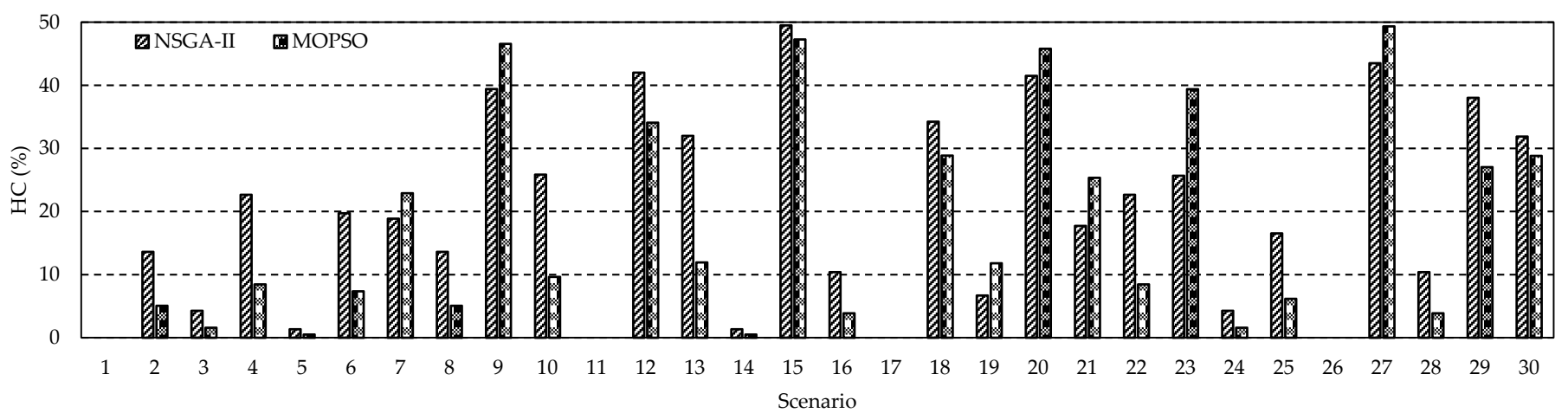

(a)

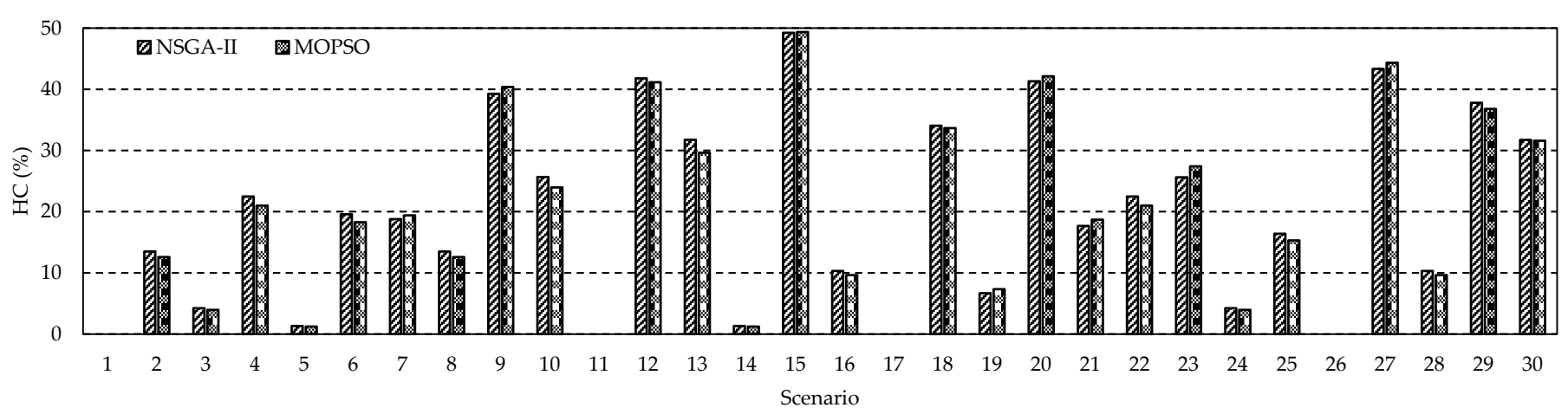

(b)

Figure 13. Cont. 


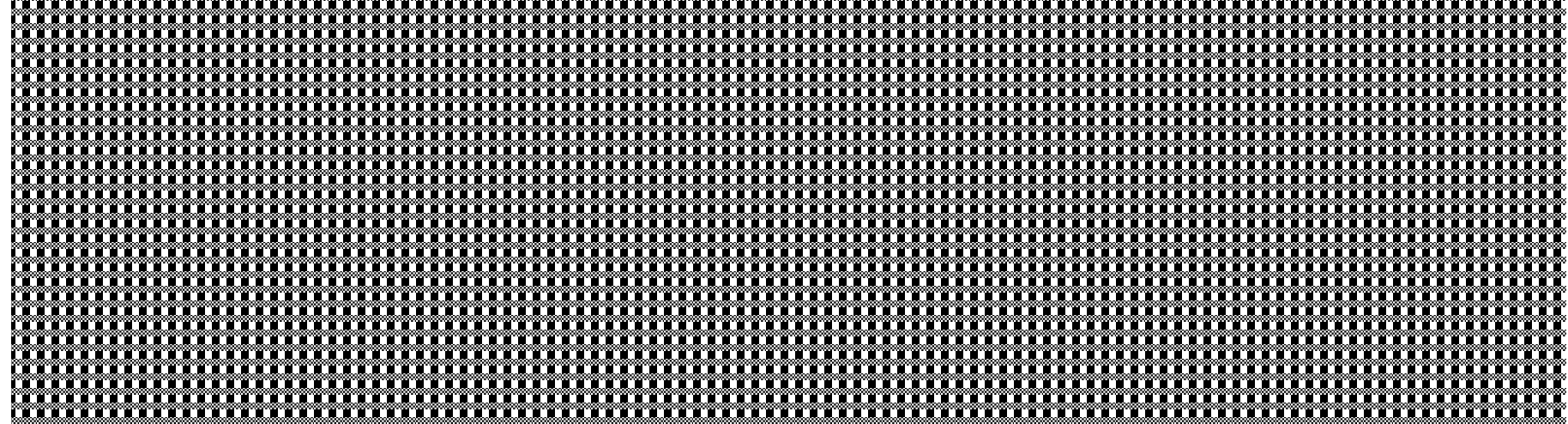

(c)

Figure 13. Hosting capacity (HC) at each scenario: (a) 59-node, (b) 83-node, and (c) 415-node.

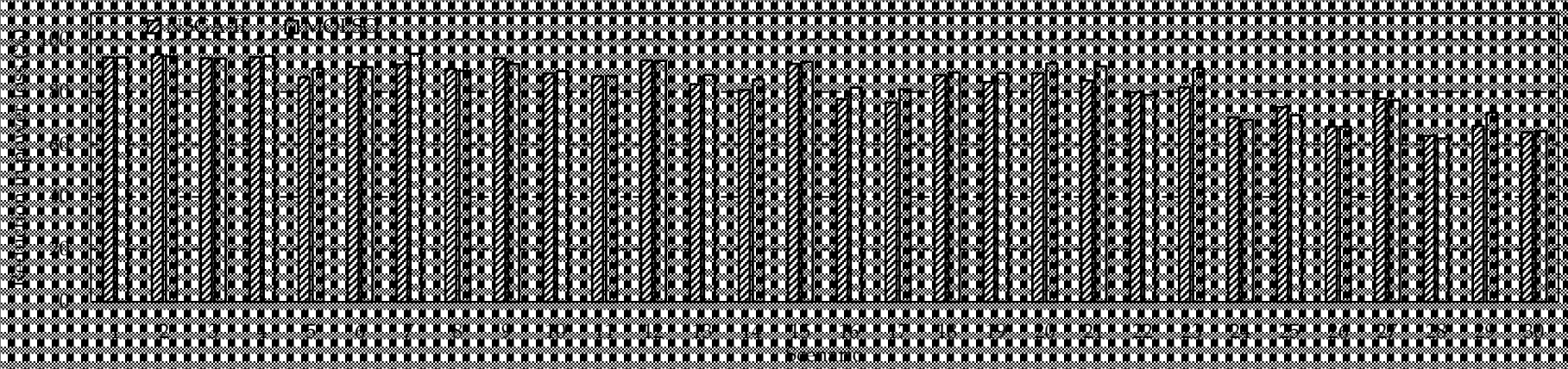

(a)

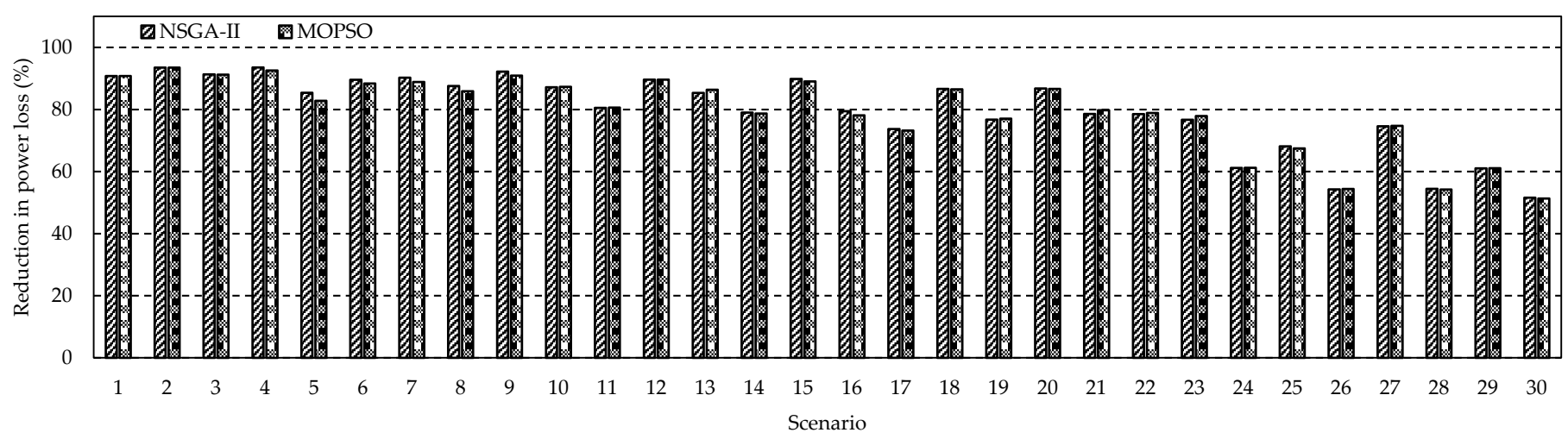

(b)

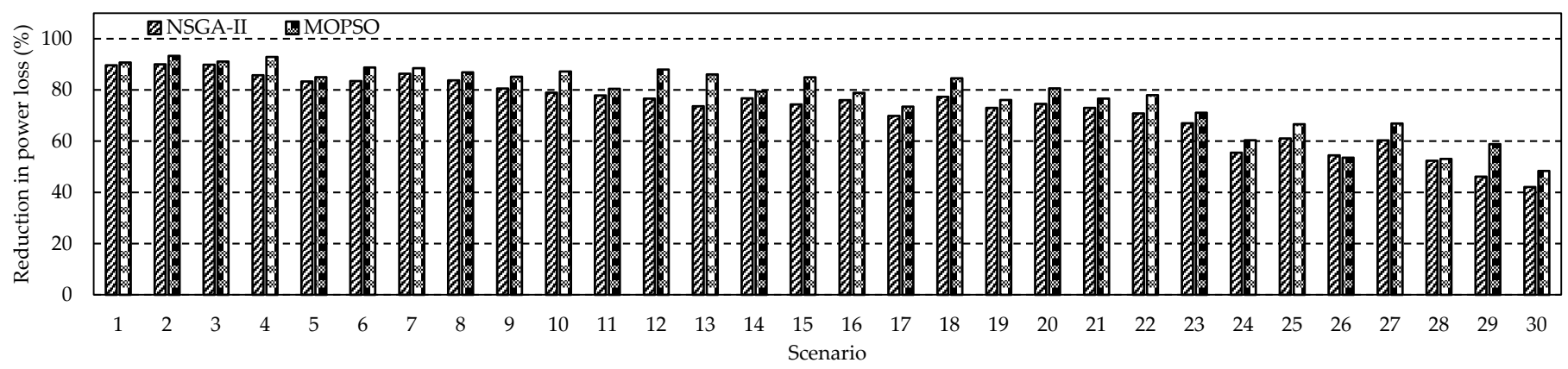

(c)

Figure 14. Reduction in power loss at each scenario: (a) 59-node, (b) 83-node, and (c) 415-node. 


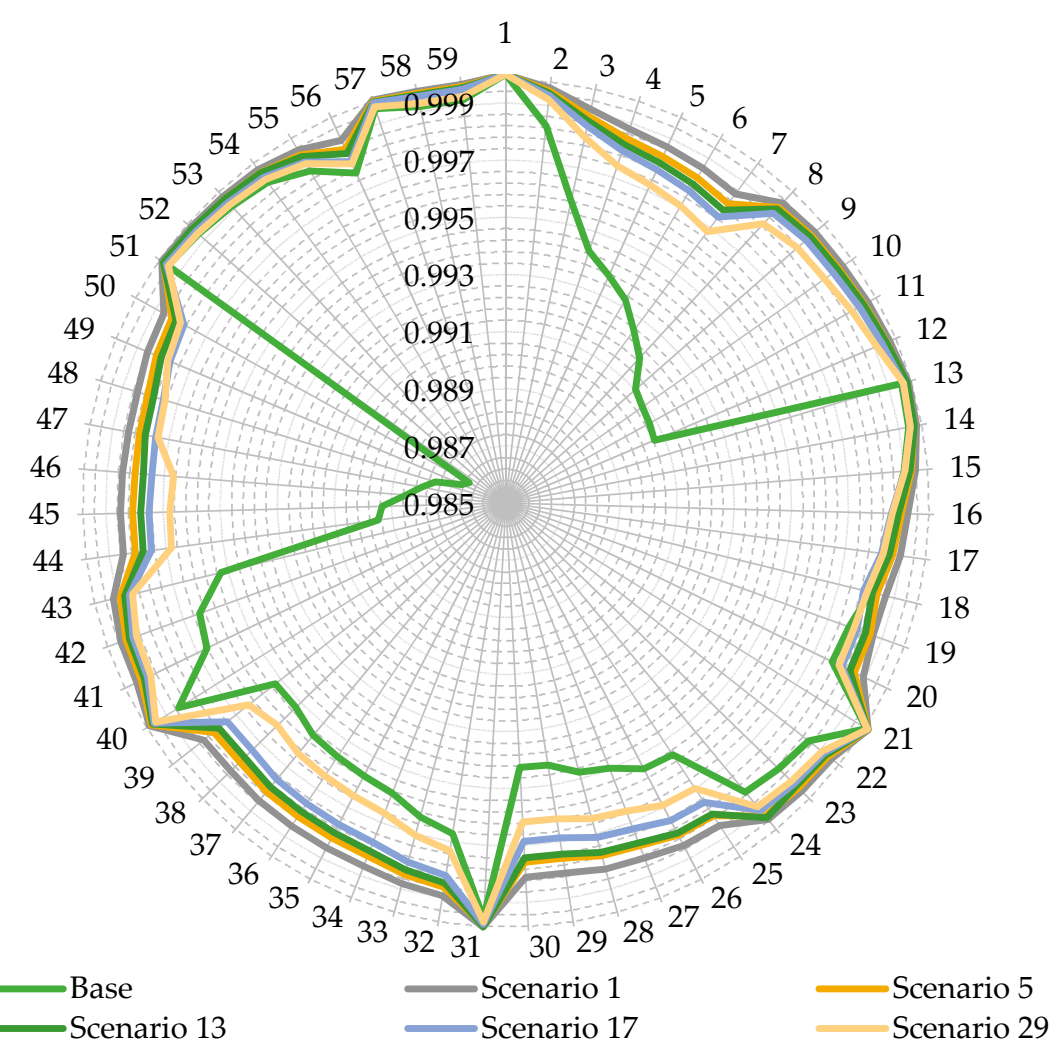

(a)

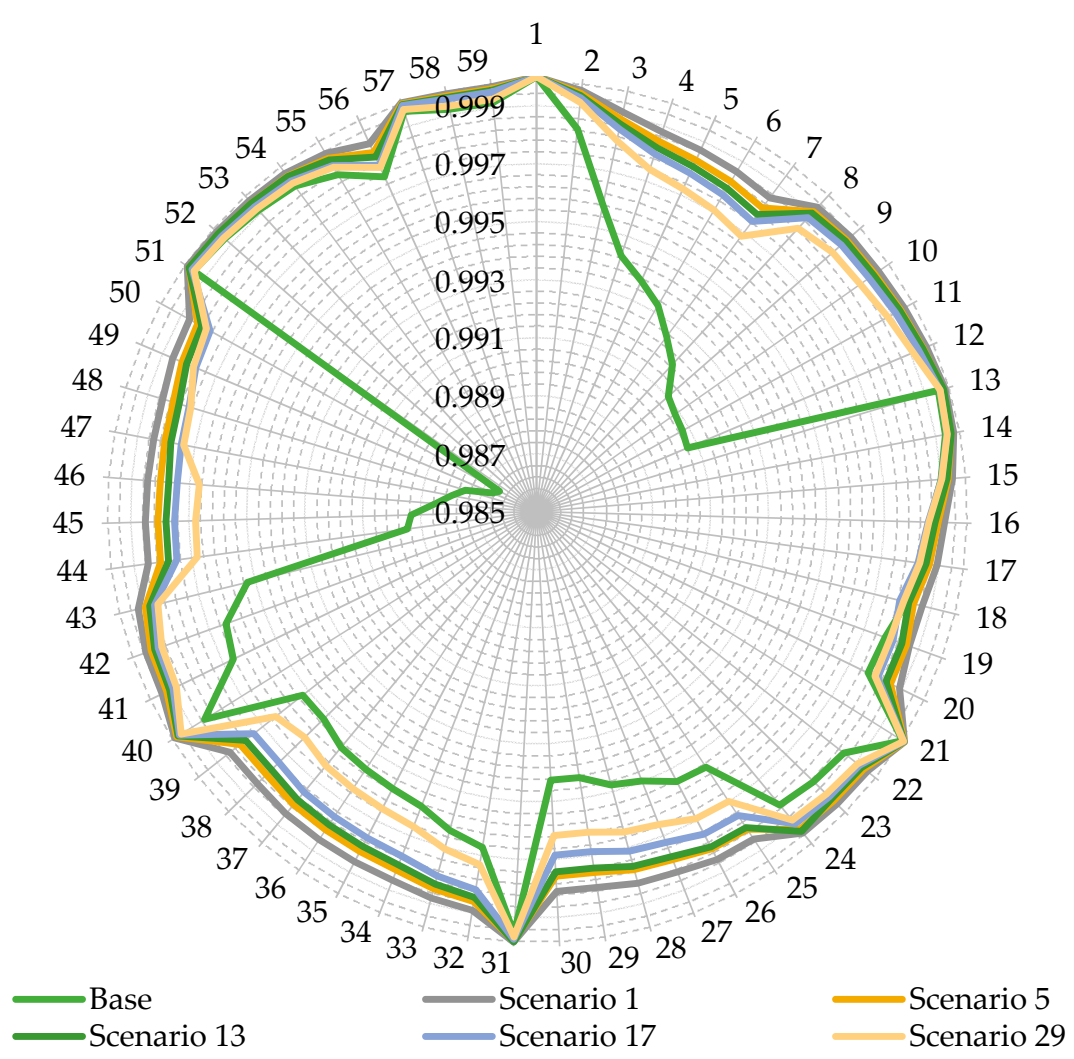

(b)

Figure 15. $\left|V_{k, s}\right|$ at multiple scenarios for the 59-node distribution network: (a) Via NSGA-II, and (b) Via MOPSO. 


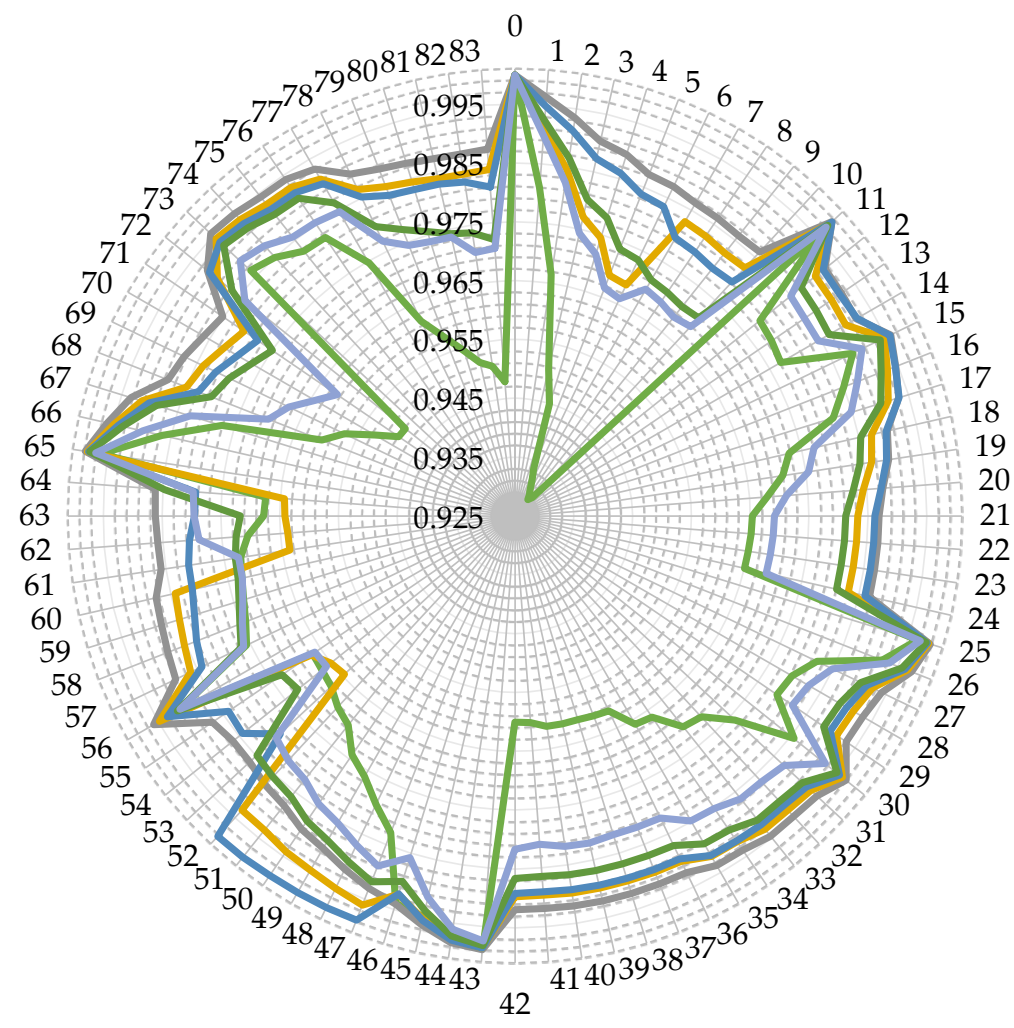

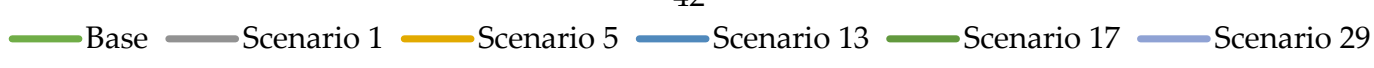

(a)

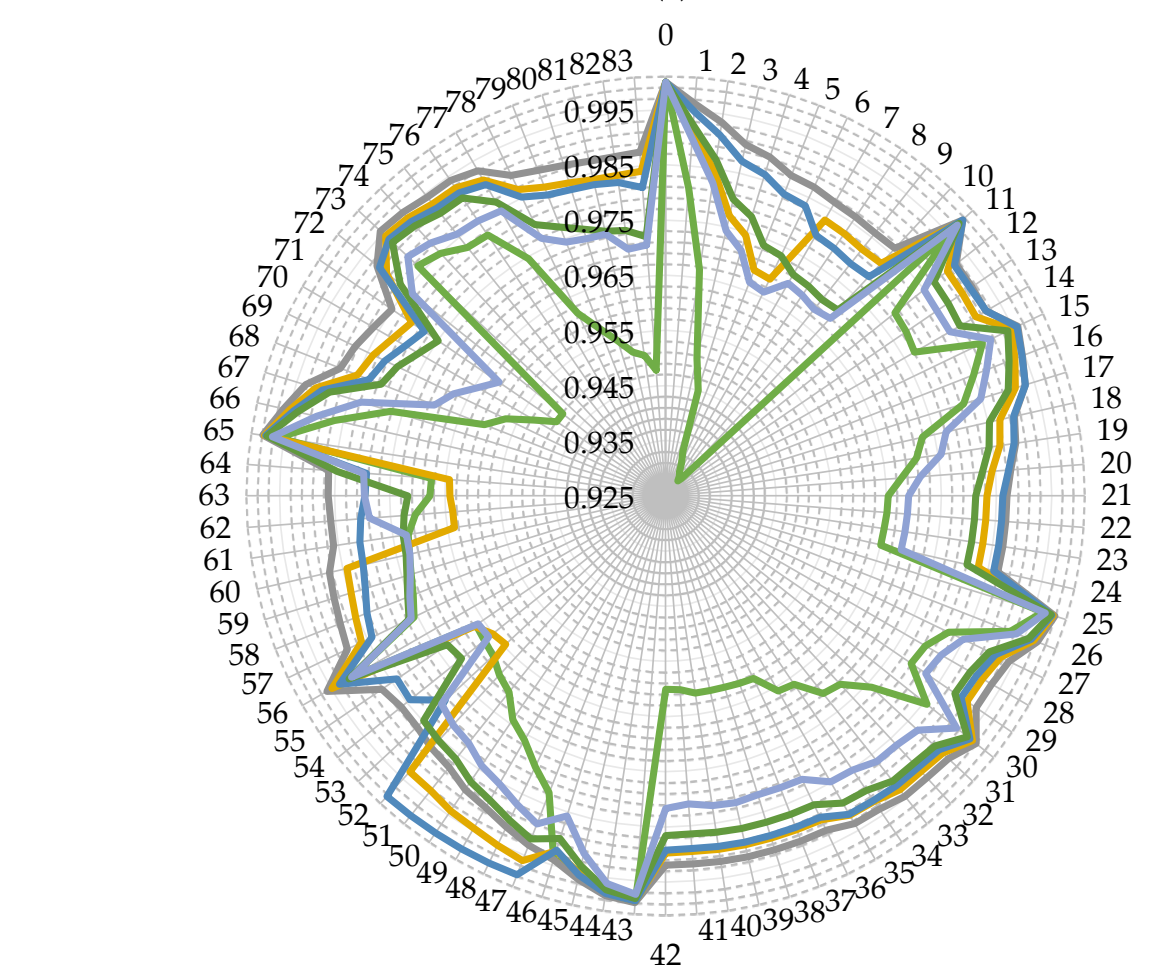

$\longrightarrow$ Base $\longrightarrow$ Scenario $1 \longrightarrow$ Scenario $5 \stackrel{42}{\longrightarrow}$ Scenario $13 \longrightarrow$ Scenario $17 \longrightarrow$ Scenario 29

(b)

Figure 16. $\left|V_{k, s}\right|$ at multiple scenarios for the 83-node distribution network: (a) Via NSGA-II, and (b) Via MOPSO. 
As a result of changing the topological structure of the studied distribution networks shown in Tables 8-12, the capability of accommodating more WT/PV DGs has increased while considering solar irradiance, wind speed, and load uncertainties. The achieved benefits from employing DNR in each scenario are illustrated as follows from the planning and operational perspectives.

From the planning perspective, the HC using the NSGA-II has reached $17.7173 \%$, while in the case of MOPSO, the HC has reached $17.5299 \%$ for the 415 -node distribution network. The power loss reduction reached for NSGA-II and MOPSO is $74.5320 \%$ and $79.2044 \%$ for the 880 -node distribution network, respectively. Thus, it is hard to assume that an optimization technique is better than the others for the proposed optimization problem. Moreover, the allocated WT/PV DGs are not suitable for all the available nodes of the distribution networks, as in the 415-node distribution network, the number of available nodes for WT, and PV DGs is 50 for each of them; however, the number of allocated WT and PV DGs is 19 and 20, respectively, using NSGA-II. Besides, at scenarios 1, 11, 17, and 26, the $\mathrm{HC}$ was zero as the solar irradiance was zero, and the wind speed was zero below its cut-in speed, thus the generated WT and PV powers were zero at these scenarios. To overcome this issue, energy storage systems (ESSs) should be optimally allocated along with WT/PV DGs allocation as a solution to overcome the problem mentioned above at times of lower irradiance and wind speeds. ESSs allocation is beyond the scope of this work and will be mentioned in upcoming future work.

From the operational perspective, three operational indices were employed to measure the improvement in the system's load balancing and voltage security, including $L B I_{o v}$, $A V D I_{o v}$, and $F V S I_{o v}$. The results obtained for these indices using NSGA-II and MOPSO are different for each distribution network, as demonstrated in Table 5. Thus, it is difficult to conclude that one of them is better than the other. From the $L B I_{o v}$ viewpoint, the $L B I_{o v}$ decreased by $30.0472 \%, 34.4887 \%, 51.7110 \%, 29.6219 \%, 11.7869 \%$, and $69.1087 \%$ for the 16-, 59-, 69-, 83-, 415-, and 880-node distribution networks using NSGA-II. From the $A V D I_{o v}$ viewpoint, the $A V D I_{o v}$ decreased by $32.4932 \%, 40.0142 \%, 62.9626 \%, 19.8607 \%$, $9.6610 \%$, and $70.2924 \%$ for the 16-, 59-, 69-, 83-, 415-, and 880-node distribution networks using NSGA-II. From the FVSI $I_{o v}$ viewpoint, the $F V S I_{o v}$ decreased by $10.0186 \%, 17.5676 \%$, $34.8239 \%, 4.4225 \%, 0.9656 \%$, and $39.7736 \%$ for the 16-, 59-, 69-, 83-, 415-, and 880-node distribution networks using NSGA-II. Moreover, the voltage profile improvement shown in Figures 13 and 14 validates the effectiveness of the proposed optimization approach independent of the used optimization technique. Finally, a multiple-scenario analysis was conducted on the 59-node distribution system to ensure the effectiveness of choosing 30 scenarios for the previous case studies. Table 13 gives insight into the effect of changing the number of generated scenarios on the obtained $\mathrm{HC}$ and power loss reduction for the 59-node distribution network in Cairo. From Table 13, it is notable that the obtained HC ranges between $17 \%$ and $19 \%$, its average is $17.9153 \%$, and its standard deviation is 0.8336 using NSGA-II. Thus, choosing 30 scenarios is relevant for our studied cases. Moreover, to ensure the effectiveness of choosing NSGA-II and MOPSO against the other multi-objective optimizers, a comparison with multi-objective multi-verse optimization (MOMVO) [42] and multi-objective flower pollination algorithm (MOFPA) [43] was conducted to step on their effectiveness. As shown in Table 14, the NSGA-II and MOPSO have provided better near-optimal solutions; however, they took a long time in computation than MOMVO and MOFPA. Besides, we aim to maximize the HC of the studied distribution systems while improving loss reduction. In this regard, NSGA-II and MOPSO were chosen to solve the optimization problem since they provided the best HC and power loss reduction. Finally, a comparison with previous works based on system's performance indices for the 83-, 415-, and 880-node distribution networks is shown in Tables 15-17, respectively, to clarify the effectiveness of the proposed optimization algorithm from the operational perspective. 
Table 13. The obtained HC and power loss reduction at different number of scenarios.

\begin{tabular}{ccccc}
\hline \multirow{2}{*}{ Number of Scenarios } & \multicolumn{2}{c}{ NSGA-II } & \multicolumn{2}{c}{ MOPSO } \\
\cline { 2 - 5 } & HC (\%) & $\boldsymbol{R P}_{\text {loss }} \mathbf{( \% )}$ & HC (\%) & $\boldsymbol{R P}_{\text {loss }} \mathbf{( \% )}$ \\
\hline 10 & 17.1015 & 83.5396 & 12.23 & 72.037 \\
20 & 18.8370 & 84.5515 & 12.02 & 80.411 \\
30 & 18.0870 & 83.3078 & 14.05 & 81.807 \\
40 & 18.5500 & 84.5329 & 11.13 & 78.225 \\
50 & 17.0012 & 84.3349 & 11.37 & 80.124 \\
Average & 17.9153 & 84.0533 & 12.16 & 78.5208 \\
Standard deviation & 0.8336 & 0.5867 & 1.1491 & 3.8428 \\
\hline
\end{tabular}

Table 14. The obtained HC and power loss reduction at different number of scenarios.

\begin{tabular}{ccccc}
\hline Optimizer & Year & HC $(\mathbf{\%})$ & $\boldsymbol{R P}_{\text {loss }}(\mathbf{\%})$ & Average Time \\
\hline NSGA-II & 2002 & $\mathbf{1 8 . 0 8 7 0}$ & $\mathbf{8 3 . 3 0 7 8}$ & 5.3130 \\
MOPSO & 2002 & 14.0500 & 81.8070 & 6.2609 \\
MOFPA & 2014 & 12.3543 & 81.1698 & 4.0531 \\
MOMVO & 2017 & 12.3953 & 72.8587 & $\mathbf{2 . 6 9 8 8}$ \\
\hline
\end{tabular}

Table 15. A comparison with previous works based on system's performance indices for the 83-node distribution network.

\begin{tabular}{cccccc}
\hline Index & Initial & [15] & [41] & [44] & Proposed \\
\hline HC (\%) & 0 & N/A & 60.71 & N/A & $\mathbf{1 7 . 9 8 7 5}$ \\
Power loss (kW) & 532.0 & 469.9 & N/A & 471.1 & $\mathbf{1 0 4 . 7 1 8}$ \\
Min voltage (p.u.) & 0.929 & 0.953 & 0.951 & 0.952 & $\mathbf{0 . 9 5 8 9}$ \\
DGs uncertainty consideration & No & N/A & No & N/A & Yes \\
Load uncertainty consideration & No & N/A & Yes & N/A & Yes \\
\hline
\end{tabular}

Table 16. A comparison with previous works based on system's performance indices for the 415-node distribution network.

\begin{tabular}{cccccc}
\hline Index & Initial & [15] & [15] & [45] & Proposed \\
\hline HC (\%) & 0 & N/A & N/A & 58.68 & $\mathbf{1 7 . 7 1 7 3}$ \\
Power loss (kW) & 2660.0 & 2350.7 & 2359.9 & 1534.3 & $\mathbf{6 7 7 . 4 4 8 8}$ \\
Min voltage (p.u.) & 0.929 & N/A & N/A & 0.951 & $\mathbf{0 . 9 5 1 1}$ \\
DGs uncertainty consideration & No & N/A & N/A & No & Yes \\
Load uncertainty consideration & No & N/A & N/A & Yes & Yes \\
\hline
\end{tabular}

Table 17. A comparison with previous works based on system's performance indices for the 880-node distribution network.

\begin{tabular}{ccccc}
\hline Index & Initial & [16] & [17] & Proposed \\
\hline HC (\%) & 0 & N/A & N/A & $\mathbf{1 8 . 0 6 9 2}$ \\
Power loss (kW) & 1496.4 & 461.0 & 461.4 & $\mathbf{9 8 . 0 6 5}$ \\
Min voltage (p.u.) & 0.956 & 0.992 & 0.982 & $\mathbf{0 . 9 5 1 1}$ \\
DGs uncertainty consideration & No & N/A & N/A & Yes \\
Load uncertainty consideration & No & N/A & N/A & Yes \\
\hline
\end{tabular}

\section{Conclusions and Future Works}

In this paper, a novel optimization approach was deployed in the form of multiobjective bilevel optimization for maximizing both the $\mathrm{HC}$ and the losses reduction percentages using a graphically based DNR mathematical approach. Five distribution networks were tested for accommodating WT and PV while considering solar, wind, and load uncertainties. In comparison with the previous works [15-17,41,45] used to improve the operational indices of the studied distribution systems, the proposed optimization approach 
via allocating WT/PV succeeded in minimizing the total active loss of the 83-, 415-, and 880 -node distribution networks by $80.7985 \%, 74.5320 \%$, and $93.5010 \%$, respectively. Furthermore, the voltage profiles shown in Figures 15 and 16 reinforce the obtained outcomes from using DNR along with WT/PVs allocation and ensures the ability of the proposed strategy to keep the voltage within its permissible limits. The proposed optimization approach succeeded in maximizing the $\mathrm{HC}$, and the power loss reduction for the studied distribution networks by greater than $17 \%$ and $74 \%$, respectively. The advantages of this work were the effectiveness of applying DNR to maximize the HC of real/large distribution networks while considering DGs uncertainties and also improving the system's operational indices and enhancing loss reduction. Other points that were not under the scope of this work and will be addressed in future works are the reliability evaluation of the obtained configurations via system average interruption frequency index (SAIFI), system average interruption duration index (SAIDI), and other reliability indices and considering other power quality issues that affect the $\mathrm{HC}$ of the distribution systems. Future works will consider the allocation of multi-terminal SOPs [46] and various energy storage types [47] along with DNR for increasing the HC of the studied distribution systems while ensuring an effective protective scheme [48]. Besides, reliability will be considered in the possible works [49-51] to provide a reliable configuration for unbalanced large/real distribution networks. Furthermore, power quality enhancement strategies will be considered while considering compliance with the IEEE standards [52].

Author Contributions: I.M.D. and S.H.E.A.A. designed the problem under study; I.M.D. performed the simulations and obtained the results; S.H.E.A.A. analyzed the obtained results; I.M.D. wrote the paper, which was further reviewed by S.H.E.A.A., A.E.-R., A.Y.A., Z.M.A., and F.J. All authors have read and agreed to the published version of the manuscript.

Funding: This project was fully funded by the Deanship of Scientific Research at Prince Sattam Bin Abdulaziz University under the research project No. 2020/01/13220.

Institutional Review Board Statement: Not applicable.

Informed Consent Statement: Not applicable.

Data Availability Statement: The data presented in this study are available on request from the corresponding author. The data are not publicly available due to its large size.

Conflicts of Interest: The authors declare no conflict of interest.

\section{Nomenclature}

Input Data and Indices

AVDI Aggregated voltage deviation index

$A V D I_{S} \quad$ Aggregated voltage deviation index at the sth scenario

$A V D I_{o v} \quad$ Overall aggregated voltage deviation index for all scenarios

$B^{\text {node }} \quad$ The set of nodes

$B^{\text {line }} \quad$ The set of lines

FVSI Aggregated fast voltage stability index

FVSI $\quad$ Aggregated FVSI for all distribution system lines at the sth scenario

$F V S I_{b, s} \quad F V S I$ of the $b$ th line at the sth scenario

$F V S I_{o v} \quad$ Overall aggregated fast voltage stability index for all scenarios

$G \quad$ Solar irradiance

$G_{s t d} \quad$ Standard solar irradiance

$G_{s} \quad$ Solar irradiance at the sth scenario

$\left|I_{b, s}\right| \quad$ Magnitude of the branch current flowing in the $b$ th branch at the sth scenario

$L L_{S} \quad$ Loading level at the sth scenario

LBI Load balancing index

$L B I_{b, s} \quad L B I$ at the sth scenario for the $b$ th line

$L B I_{S} \quad$ Aggregated LBI for all lines at the sth scenario

$L B I_{o v} \quad$ Overall LBI for all scenarios

$N^{s} \quad$ Total number of scenarios 


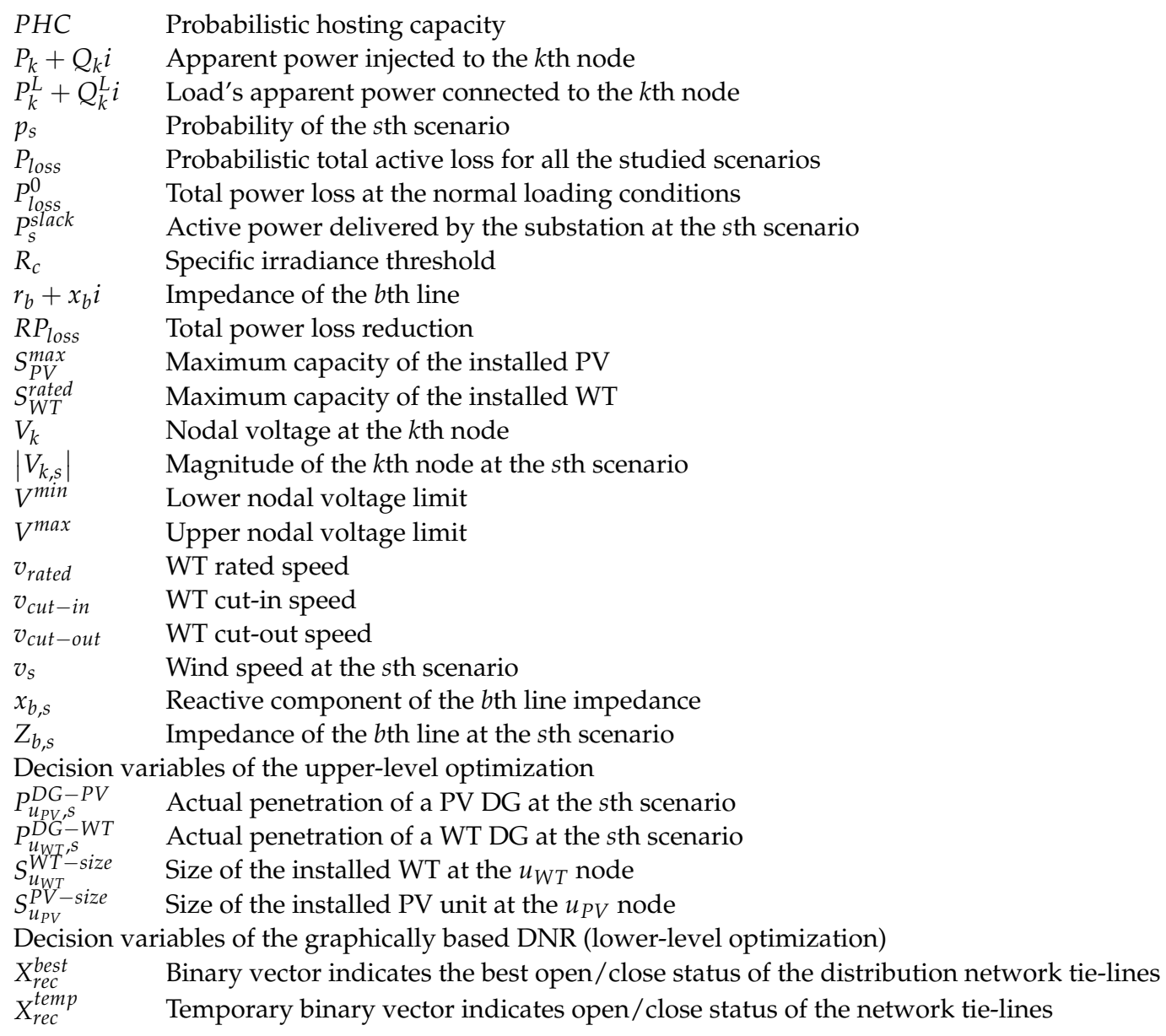

\section{References}

1. Zappa, W.; Junginger, M.; van den Broek, M. Is a 100\% renewable European power system feasible by 2050? Appl. Energy 2019, 233-234, 1027-1050. [CrossRef]

2. Zsiborács, H.; Baranyai, N.H.; Vincze, A.; Zentkó, L.; Birkner, Z.; Máté, K.; Pintér, G. Intermittent Renewable Energy Sources: The Role of Energy Storage in the European Power System of 2040. Electronics 2019, 8, 729. [CrossRef]

3. Ismael, S.M.; Abdel Aleem, S.H.E.; Abdelaziz, A.Y.; Zobaa, A.F. State-of-the-art of hosting capacity in modern power systems with distributed generation. Renew. Energy 2019, 130, 1002-1020. [CrossRef]

4. Sakar, S.; Balci, M.E.; Abdel Aleem, S.H.E.; Zobaa, A.F. Increasing PV hosting capacity in distorted distribution systems using passive harmonic filtering. Electr. Power Syst. Res. 2017, 148, 74-86. [CrossRef]

5. Diaaeldin, I.; Abdel Aleem, S.; El-Rafei, A.; Abdelaziz, A.; Zobaa, A.F. Optimal Network Reconfiguration in Active Distribution Networks with Soft Open Points and Distributed Generation. Energies 2019, 12, 4172. [CrossRef]

6. Alalamat, F. Increasing the Hosting Capacity of Radial Distribution Grids in Jordan, n.d. Available online: http:/ / www.teknat. uu.se/student (accessed on 3 June 2020).

7. Takenobu, Y.; Yasuda, N.; Minato, S.; Hayashi, Y. Scalable enumeration approach for maximizing hosting capacity of distributed generation. Int. J. Electr. Power Energy Syst. 2019, 105, 867-876. [CrossRef]

8. Capitanescu, F.; Ochoa, L.F.; Margossian, H.; Hatziargyriou, N.D. Assessing the Potential of Network Reconfiguration to Improve Distributed Generation Hosting Capacity in Active Distribution Systems. IEEE Trans. Power Syst. 2015, 30, 346-356. [CrossRef]

9. Diaaeldin, I.M.; Abdel Aleem, S.H.E.; El-Rafei, A.; Abdelaziz, A.Y.; Zobaa, A.F. Hosting Capacity Maximization Based on Optimal Reconfiguration of Distribution Networks with Optimized Soft Open Point Operation. In Hosting Capacity for Smart Power Grids; Springer International Publishing: Cham, Switzerland, 2020; pp. 179-193, ISBN 9783030400293.

10. Qi, Q.; Long, C.; Wu, J.; Smith, K.; Moon, A.; Yu, J. Using an MVDC Link to Increase DG Hosting Capacity of a Distribution Network. Energy Procedia 2017, 142, 2224-2229. [CrossRef]

11. Ismael, S.M.; Abdel Aleem, S.H.E.; Abdelaziz, A.Y.; Zobaa, A.F. Practical Considerations for Optimal Conductor Reinforcement and Hosting Capacity Enhancement in Radial Distribution Systems. IEEE Access 2018, 6, 27268-27277. [CrossRef]

12. Ismael, S.; Abdel Aleem, S.; Abdelaziz, A.; Zobaa, A. Probabilistic Hosting Capacity Enhancement in Non-Sinusoidal Power Distribution Systems Using a Hybrid PSOGSA Optimization Algorithm. Energies 2019, 12, 1018. [CrossRef]

13. Pandi, V.R.; Zeineldin, H.H.; Xiao, W.; Zobaa, A.F. Optimal penetration levels for inverter-based distributed generation considering harmonic limits. Electr. Power Syst. Res. 2013, 97, 68-75. [CrossRef] 
14. Xu, X.; Li, J.; Xu, Z.; Zhao, J.; Lai, C.S. Enhancing photovoltaic hosting capacity-A stochastic approach to optimal planning of static var compensator devices in distribution networks. Appl. Energy 2019, 238, 952-962. [CrossRef]

15. Jabr, R.A.; Singh, R.; Pal, B.C. Minimum Loss Network Reconfiguration Using Mixed-Integer Convex Programming. IEEE Trans. Power Syst. 2012, 27, 1106-1115. [CrossRef]

16. Ahmadi, H.; Marti, J.R. Distribution System Optimization Based on a Linear Power-Flow Formulation. IEEE Trans. Power Deliv. 2015, 30, 25-33. [CrossRef]

17. Taylor, J.A.; Hover, F.S. Convex Models of Distribution System Reconfiguration. IEEE Trans. Power Syst. 2012, $27,1407-1413$. [CrossRef]

18. Mohamed Diaaeldin, I.; Abdel Aleem, S.H.E.; El-Rafei, A.; Abdelaziz, A.Y.; Zobaa, A.F. A Novel Graphically-Based Network Reconfiguration for Power Loss Minimization in Large Distribution Systems. Mathematics 2019, 7, 1182. [CrossRef]

19. Badran, O.; Mekhilef, S.; Mokhlis, H.; Dahalan, W. Optimal reconfiguration of distribution system connected with distributed generations: A review of different methodologies. Renew. Sustain. Energy Rev. 2017, 73, 854-867. [CrossRef]

20. Abdelaziz, A.Y.; Mohamed, F.M.; Mekhamer, S.F.; Badr, M.A.L. Distribution system reconfiguration using a modified Tabu Search algorithm. Electr. Power Syst. Res. 2010, 80, 943-953. [CrossRef]

21. Diaaeldin, I.M.; Abdel Aleem, S.H.E.; El-Rafei, A.; Abdelaziz, A.Y. A Novel Reconfiguration Methodology of Radial Distribution Systems for Power Loss Minimization Using Expanded Invasive Weed optimization. In Proceedings of the 2019 21st International Middle East Power Systems Conference (MEPCON), Cairo, Egypt, 17-19 December 2019; IEEE: New York, NY, USA, 2019 ; pp. 119-124.

22. Eldurssi, A.M.; O'Connell, R.M. A Fast Nondominated Sorting Guided Genetic Algorithm for Multi-Objective Power Distribution System Reconfiguration Problem. IEEE Trans. Power Syst. 2015, 30, 593-601. [CrossRef]

23. Roberge, V.; Tarbouchi, M.; Okou, F.A. Distribution System Optimization on Graphics Processing Unit. IEEE Trans. Smart Grid 2017, 8, 1689-1699. [CrossRef]

24. Deb, K.; Pratap, A.; Agarwal, S.; Meyarivan, T. A fast and elitist multiobjective genetic algorithm: NSGA-II. IEEE Trans. Evol. Comput. 2002, 6, 182-197. [CrossRef]

25. Coello Coello, C.A.; Lechuga, M.S. MOPSO: A proposal for multiple objective particle swarm optimization. In Proceedings of the 2002 Congress on Evolutionary Computation. CEC'02 (Cat. No.02TH8600), Honolulu, HI, USA, 12-17 May 2002; IEEE: New York, NY, USA, 2002; Volume 2, pp. 1051-1056.

26. Mohamed Diaaeldin, I.; Abdel Aleem, S.H.E.; El-Rafei, A.; Abdelaziz, A.Y.; Zobaa, A.F. Distribution System Reconfiguration for an Egyptian Distribution Feeder; Mendeley Data: Amesterdam, The Netherlands, 2020; Volume 1. [CrossRef]

27. Zimmerman, R.D.; Murillo-Sanchez, C.E.; Thomas, R.J. MATPOWER: Steady-State Operations, Planning, and Analysis Tools for Power Systems Research and Education. IEEE Trans. Power Syst. 2011, 26, 12-19. [CrossRef]

28. Zimmerman, R.D.; Murillo-Sanchez, C.E. MATPOWER (Version 4.1) [Software]. 2011. Available online: https://matpower.org (accessed on 9 November 2020). [CrossRef]

29. Surender Reddy, S.; Bijwe, P.R.; Abhyankar, A.R. Real-Time Economic Dispatch Considering Renewable Power Generation Variability and Uncertainty Over Scheduling Period. IEEE Syst. J. 2015, 9, 1440-1451. [CrossRef]

30. Biswas, P.P.; Suganthan, P.N.; Mallipeddi, R.; Amaratunga, G.A.J. Optimal reactive power dispatch with uncertainties in load demand and renewable energy sources adopting scenario-based approach. Appl. Soft Comput. 2019, 75, 616-632. [CrossRef]

31. Available online: https://drive.google.com/drive/folders/1wdnc_Wizv5QYGz7NEx2XG52_HO6ET1bA?usp=sharing (accessed on 9 November 2020).

32. Growe-Kuska, N.; Heitsch, H.; Romisch, W. Scenario reduction and scenario tree construction for power management problems. In Proceedings of the 2003 IEEE Bologna Power Tech Conference Proceedings, Bologna, Italy, 23-26 June 2003; IEEE: New York, NY, USA, 2003; Volume 3, pp. 152-158.

33. Hwang, C.-L.; Yoon, K. Multiple Attributes Decision Making Methods and Applications. 1981. Available online: https://www. springer.com/gp/book/9783540105589 (accessed on 21 December 2020).

34. Yoon, K. A Reconciliation among Discrete Compromise Solutions. J. Oper. Res. Soc. 1987, 38, 277. [CrossRef]

35. Hwang, C.-L.; Lai, Y.-J.; Liu, T.-Y. A new approach for multiple objective decision making. Comput. Oper. Res. 1993, 20, 889-899. [CrossRef]

36. Baran, M.E.; Wu, F.F. Network reconfiguration in distribution systems for loss reduction and load balancing. IEEE Trans. Power Deliv. 1989, 4, 1401-1407. [CrossRef]

37. Othman, A.M.; El-Fergany, A.A.; Abdelaziz, A.Y. Optimal Reconfiguration Comprising Voltage Stability Aspect Using Enhanced Binary Particle Swarm Optimization Algorithm. Electr. Power Compon. Syst. 2015, 43, 1656-1666. [CrossRef]

38. Diaaeldin, I.M.; Abdel Aleem, S.H.E.; El-Rafei, A.; Abdelaziz, A.Y.; Calasan, M. Optimal Network Reconfiguration and Distributed Generation Allocation using Harris Hawks Optimization. In Proceedings of the 2020 24th International Conference on Information Technology (IT), Zabljak, Montenegro, 18-22 February 2020; IEEE: New York, NY, USA, 2020; pp. 1-6.

39. Available online: http:// roberge.segfaults.net/joomla/index.php (accessed on 9 November 2020).

40. Saleh, O.A.; Elshahed, M.; Elsayed, M. Enhancement of radial distribution network with distributed generation and system reconfiguration. J. Electr. Syst. 2018, 14, 36-50.

41. Diaaeldin, I.M.; Abdel Aleem, S.H.E.; El-Rafei, A.; Abdelaziz, A.Y.; Zobaa, A.F. Enhancement of Hosting Capacity with Soft Open Points and Distribution System Reconfiguration: Multi-Objective Bilevel Stochastic Optimization. Energies 2020, 13, 5446. [CrossRef] 
42. Yang, X.-S.; Karamanoglu, M.; He, X. Flower pollination algorithm: A novel approach for multiobjective optimization. Eng. Optim. 2014, 46, 1222-1237. [CrossRef]

43. Mirjalili, S.; Jangir, P.; Mirjalili, S.Z.; Saremi, S.; Trivedi, I.N. Optimization of problems with multiple objectives using the multi-verse optimization algorithm. Knowl. Based Syst. 2017, 134, 50-71. [CrossRef]

44. Wu, W.-C.; Tsai, M.-S. Application of enhanced integer coded particle swarm optimization for distribution system feeder reconfiguration. IEEE Trans. Power Syst. 2011, 26, 1591-1599. [CrossRef]

45. Diaaeldin, I.M.; Abdel Aleem, S.H.E.; El-Rafei, A.; Abdelaziz, A.Y.; Zobaa, A.F. Large-scale integration of distributed generation in reconfigured distribution networks considering load uncertainty. In Uncertainties in Modern Power Systems; Elsevier: Amsterdam, The Netherlands, 2021; pp. 441-484.

46. Escalera, A.; Prodanović, M.; Castronuovo, E.D.; Roldan-Perez, J. Contribution of active management technologies to the reliability of power distribution networks. Appl. Energy 2020, 267, 114919. [CrossRef]

47. Mostafa, M.H.; Abdel Aleem, S.H.E.; Ali, S.G.; Ali, Z.M.; Abdelaziz, A.Y. Techno-economic assessment of energy storage systems using annualized life cycle cost of storage (LCCOS) and levelized cost of energy (LCOE) metrics. J. Energy Storage 2020, $29,101345$. [CrossRef]

48. Abdul Rahim, M.N.; Mokhlis, H.; Bakar, A.H.A.; Rahman, M.T.; Badran, O.; Mansor, N.N. Protection Coordination Toward Optimal Network Reconfiguration and DG Sizing. IEEE Access 2019, 7, 163700-163718. [CrossRef]

49. Amanulla, B.; Chakrabarti, S.; Singh, S.N. Reconfiguration of Power Distribution Systems Considering Reliability and Power Loss. IEEE Trans. Power Deliv. 2012, 27, 918-926. [CrossRef]

50. Ghasemi, S. Balanced and unbalanced distribution networks reconfiguration considering reliability indices. Ain Shams Eng. J. 2018, 9, 1567-1579. [CrossRef]

51. Swief, R.; Abdel-Salam, T.; El-Amary, N. Photovoltaic and Wind Turbine Integration Applying Cuckoo Search for Probabilistic Reliable Optimal Placement. Energies 2018, 11, 139. [CrossRef]

52. Abdel Aleem, S.H.E.; Elmathana, M.T.; Zobaa, A.F. Different Design Approaches of Shunt Passive Harmonic Filters Based on IEEE Std. 519-1992 and IEEE Std. 18-2002. Recent Pat. Electr. Electron. Eng. 2013, 6, 68-75. [CrossRef] 